\title{
Neoplasia Intraepitelial Cervical en el Hospital Materno Infantil $1978-1982$
}

\author{
Dres.: Miguel Eduardo Aragón*, Ariel Iván Ruiz Parra** \\ y Jacinto Sánchez Angarita**.
}

\section{INTRODUCCION}

\section{A.N.I.C.: EPIDEMIOLOGIA Y ETIOLOGIA}

Gracias a la accesibilidad del cervix, se ha estudiado extensamente el cáncer invasivo y sus precursores con técnicas citológicas, histológicas, clínicas y de laboratorio. Hoy se acepta que la mayoría de los cánceres invasivos fueron precedidos por una etapa precursora del desarrollo que se caracteriza morfológicamente por alteraciones nucleares y citoplasmáticas que incluyen: aumento del tamaño nuclear, hipercromasia, aumento del número de mitosis (normales y anormales), alteraciones en la disposición celular (polaridad) y diferenciación citoplasmática incompleta, anormal o ausente. (1) Se han usado ampliamente los términos "Displasia" y "Carcinoma in situ

\footnotetext{
Instructor Asociado.

** Residente III.
}

(CIS)" (2) y, más recientemente, el de "Neoplasia Intraepitelial Cervical (NIC)", (3) para designar estos cambios.

El término Neoplasia Intraepitelial Cervical intenta combinar la terminología histórica de Displasia Leve, Moderada, Severa y Carcinoma in situ, en un continuum de un proceso epitelial con el potencial de progresar a lesión cervical invasiva. Se cita un período de 58 a 86 meses para que la displasia leve (NIC 1) progrese a displasia severa y carcinoma in situ (NIC 3).

Sin embargo, hay datos que muestran que no todas las pacientes con cambios displásicos leves progresan a través de este espectro hasta enfermedad invasiva. La NIC es el resultado de alteraciones en los procesos de proliferación y maduración (diferenciación) de la capa basal del epitelio pavimentoso y de las células de reserva del epitelio cilíndrico cervicales. Se denomina NIC 1 cuando los cambios displásicos sustituyen el tercio inferior 
o profundo del epitelio cervical; NIC 2 cuando sustituyen los dos tercios inferiores y NIC 3 cuando los cambios displásicos sustituyen más de los dos tercios del epitelio cervical. El Carcinoma in situ es la lesión en la cual todo el espesor del epitelio cervical está remplazado por células que microscópicamente no pueden distinguirse de las de un cáncer invasor, con pérdida total de la estratificación pero sin invasión al estroma y sin metástasis.

Las concepciones respecto a la patogénesis de la enfermedad han cambiado con el tiempo; quizá el avance del conocimiento sobre la NIC comienza con Sauter quien practicó la primera histerectomía vaginal en 1821, iniciándose un proceso que hizo disponibles especímenes para la comunidad de investigadores biomédicos. (5) Dos décadas después Rigoni-Stern revisó los registros de estadísticas vitales de Verona (Italia) entre 1760 y 1839 y observó una relación inversa entre los carcinomas del cervix y del seno: mientras este era más frecuente entre solteras y religiosas, el cáncer uterino era inusitadamente raro entre ellas. El especul6 que la susceptibilidad del útero al cáncer podía variar con el "ejercicio natural de sus funciones". Al practicarse la primera histerectomía abdominal bajo anestesia general en 1846, los patólogos y otros investigadores tuvieron úteros disponibles para estudio. En esta época Broussais y luego Virchow relacionaron la neoplasia con la irritación crónica o el trauma: en el caso del cervix implicaba laceraciones recurrentes, abrasiones e infecciones asociadas con pobre cuidado obstétrico o multiparidad, como factores causales. Esto proporcionó una explicación para el riesgo desproporcionadamente alto para sufrir cáncer uterino en las mujeres de clases socioeconómicas bajas (5).
En Nueva York un ginecólogo revisando su material clínico desde 1893 hasta 1906, observó que el cáncer cervical era veinte veces menos frecuente en mujeres judías comparadas con las de otras razas. Esta observación fue ampliamente documentada luego en Europa, Estados Unidos, Canadá e Israel y se le atribuyó inicialmente a factores genéticos, a seguimiento de la Ley Mosaica sobre el intercurso sexual e incluso a prácticas dietéticas rituales. En 1935 Handley sugirió que la frecuencia relativamente baja del cáncer cervical en mujeres judías podía deberse a la "protección que ofrece la operación higiénica de la circuncisión contra las infecciones bacterianas del cervix durante el coito" (4).

Con la publicación de Papanicolau y Traut sobre la citología exfoliativa en 1943 , se dio el primer paso hacia la prevención y control del cáncer cervical. Entre 1950 y 1967, se realizaron los primeros estudios epidemiológicos sobre factores de riesgo de la neoplasia cervical y desde finales de 1960 numerosos grupos de clínicos, virólogos y epidemiólogos aumentaron sus esfuerzos de relacionar el cáncer con un microorganismo de transmisión vénérea cuyo comportamiento biológico e inmunológico fuera consistente con el de un carcinógeno cervical. Varias décadas de observaciones clínicas y de investigaciones epidemiológicas han confirmado que el carcinoma escamoso del cervix se comporta como una enfermedad venérea (5).

Los factores epidemiológicos que se han relacionado con la carcinogénesis cervical se pueden resumir en:

\section{Coito, matrimonio y embarazo}

Muchos estudios implican el coito y el matrimonio en la etiología del cáncer 
cervical. En un análisis de mortalidad en Estados Unidos entre 1959 y 1961, se encontraron tasas de mortalidad por cáncer cervical significativamente más bajas en mujeres solteras comparadas con las casadas, viudas o divorciadas en todas las edades. Probablemente el factor más importante es la edad del primer coito que tiende a ser más temprana en las pacientes con carcinoma cervical $(6,7,8,9)$. El cáncer cervical es más frecuente en mujeres que han tenido más compañeros sexuales, prostitutas, multíparas, separadas o viudas, mujeres que mantienen relaciones extramaritales sexuales y que pertenecen a las clases socioeconómicas más bajas $(5,8,9,10,11)$.

\section{Factores masculinos}

Estos probablemente guardan relación con factores infecciosos. La proporción de esposos no circuncidados es considerablemente mayor en mujerescon cáncer cervical que en controles (12). También se ha reportado que el número de compañeras sexuales reportadas por el marido es un factor de riesgo significativo para cáncer cervical en su esposa, con un riesgo relativo de 7.8 para quince o más compañeras fuera del matrimonio (13). Se han hecho estudios del esmegma como posible carcinógeno con resultados contradictorios y se ha sugerido que los espermatozoides pueden ser mutagénicos para el cervix en condiciones particulares (14). Parece además, que factores del esperma pueden influir el desarrollo atípico inducido por el Herpes-virus de tipo 2 (22).

\section{Lúes y tricomoniasis}

Durante la década del 50 se hicieron varios estudios epidemiólógicos que brindaron informació: s sobre la prevalencia de lá sífilis en pacientes con cáncer cervi- cal, pero hoy se acepta que tal asociación es secundaria y proviene de la relación de ambos factores con factores transmitidos sexualmente (5). La tricomoniasis es más prevalente en mujeres con inflamaciones, displasia y carcinoma cervical $y$, las mujeres con tricomoniasis prèsentan más frecuentemente frotis cervicales anormales que las otras mujeres (15). Esta asociación posiblemente también es función de su forma de transmisión.

\section{Herpes-virus tipo 2}

Está fuera del alcance de este trabajo reunir la gran información que relaciona el Herpes-virus tipo 2 (HV-2) con el carcinoma cervical; baste decir que la demostración de tal relación proviene de estudios en los que se ha encontrado: $(5,8,9,16,17,18,19,20$, 21).

a. Evidencia citológica de infección herpética activa en biopsias de cervix con anaplasia (carcinoma o atipia escamosa).

b. Asociación positiva entre cáncer cervical y anticuerpos anti-HV-2.

c. Presencia de antígenos de HV-2 en células de cáncer cervical exfoliadas, de DNA viral del HV-2 y de RNAm en tejido tumoral cervical y litiración de viriones $\mathrm{HV}-2$ y de virus infecciosos de tejido de biopsia de cáncer cervical.

d. Posible asociación de cepas de HV con tumores de pájaros, monos y ranas.

e. Posible papel del HV en por lo menos otras tres formas de neoplasia humana: 
linfomas, cáncer de nasofaringe y de labios.

f. Transmisión venérea del virus y comportamiento del carcinoma escamoso como enfermedad venérea.

\section{Papiloma-virus}

Las siguientes observaciones sugieren el posible papel del papilomavirus humano (PVH) como agente oncogénico: $(6$, $23,24,25,26,27)$.

a. El PVH es un miembro de los papovavirus y virus de este grupo tienen el potencial oncogenético demostrado en animales experimentales.

b. Se han reportado cambios malignos en condilomas vulvares.

c. Hay relación estrecha entre condiloma cervical y NIC temprana que sugiere que el virus puede ser activo en el desarrollo de precursores de cáncer cervical.

d. El PVH es altamente contagioso y se transmite por contacto sexual.

e. Es relativamente común la infección por PVH del epitelio metaplásico en la zona de transformación.

f. La infección subclínica por PVH coexiste comúnmente con focos de NIC.

g. Se han transformado células de cultivo de tejido de un fenotipo normal a uno neoplásico con papilomavirus animales.

h. Hay datos preliminares que reportan la demostración de secuencias genómicas del virus en células tumorales.

i. Se encontraron niveles más altos de IgG contra un antígeno específico del grupo PV en pacientes con verrugas genitales, NIC y carcinoma escamoso invasivo del cervix, que en controles; el grupo de cáncer invasivo tuvo el título promedio mayor comparado con el de NIC o el de verrugas genitales.

\section{Factores metabólicos}

Finalmente, se han publicado estudios preliminares acerca de deficiencia de vitaminas A y C, Beta-caroteno, Proteína ligadora de retinol y Folatos como posibles factores relacionados con la NIC (2, $8,29,30)$. La identificación de todos los factores mencionados llevará a una mejor comprensión del fenómeno carcinogenético y su aplicación implicará medidas profilácticas más efectivas.

\section{B. METODOS DIAGNOSTICOS}

La tasa de mortalidad por cáncer cervical ha disminuido significativamente en los últimos años gracias al diagnóstico temprano; (31) se ha observado incidencia cada vez menor de casos de cáncer invasivo diagnosticados de novo, incidencia creciente de casos nuevos de cáncer in situ del cervix y creciente incidencia del diagnóstico en etapas tempranas del cáncer cervical. Los métodos diagnósticos de que disponemos son:

\section{Citología}

Se sugiere que las tendencias favorables en el diagnóstico de las lesiones cervicales se deben a la utilización creciente de las pruebas de Papanicolaou (21). EI 
American College of Obstetricians and Gynecologists reafirmó el valor de la selección citológica anual. Cuando se diagnostica CA por evaluaciones anuales rutinarias se mejoran las posibilidades por encontrarse una lesión menor, más favorable desde el punto de vista pronóstico y por una terapia más simple. Un "efecto colateral" de la selección anual con frotis de Papanicolaou es permitir la oportunidad de examinar los senos, evaluar otros sistemas y practicar examen pélvico para detectar tumores de ovario y otras patologías. Los beneficios adicionales de la visita anual pueden sobrepasar los problemas financieros en los individuos y la sociedad (32). La citología permite además descubrir cambios citólógicos morfológicos propios de la infección por PVH: coilocitosis (halo perinuclear claro), multinucleación, paraqueratosis o disqueratosis; hoy se diagnostica la infección por PVH en 1 a $10 \%$ de todos los frotis de Papanicolaou (23). Con éste procedimiento diagnóstico sencillo se puede entonces documentar la asociación de PVH y NIC.

\section{Colposcopia}

Al lado de la citología, el diagnóstico de la NIC puede establecerse con precisión con el uso del colposcopio, eliminando la necesidad de la conización de tipo diagnóstico en más del $80 \%$ de pacientes pues permite analizar la localización, extensión y severidad de la lesión cervical y dirigir la biopsia a las áreas indicadas (33). La técnica colposcópica se basa en las diferencias que ocurren en el patrón vascular de la enfermedad cervical benigna, NIC y cáncer invasivo. La aplicación de ácido acético al 3-5\% al cervix vuelve blanco el epitelio normal, aumenta el contraste vascular y facilita el diagnóstico diférencial. Debe entenderse que el diag- nóstico diferencial entre cambios cervicales benignos, NIC e invasión requiere siempre un examen histológico del cervix basado en biopsias tomadas con la asistencia colposcópica. Es inaceptable tratar una paciente con base solamente en el examen colposcópico, pués puede errarse el diagnóstico de un cáncer invasivo sin una confirmación histológica cuidadosa de los hallazgos colposcópicos.

El cervix debe visualizarse completamente para determinar la extensión de la enfermedad y predecir su naturaleza; ésto requiere el uso del espéculo más grande que la vagina puede tolerar confortablemente y que sus hojas permanezcan paralelas. Antes de colocar el espéculo, se debe examinar con el colposcopio la vulva y el introito en una mujer con frotis anormal ya que las pacientes con NIC tienen al to riesgo de desarrollar neoplasia vulvar. Por el al to riesgo de una lesión vaginal concomitante, también se debe examinar la vagina al retirar el espéculo por rotación lenta durante su extracción, examinando colposcópicamente los pliegues vaginales. Se debe prestar particular atención a los fórnices vaginales $y$ al tercio superior de vagina para detectar una extensión de lesión cervical o focos independientes de neoplasia vaginal (34).

La clave para un buen examen colposcópico es el ácido acético al 3-5\%. La mejor forma de aplicación es con una torunda de algodón o un aplicador grande. Algunos recomiendan limpiar el cervix con solución salina y examinarlo colposcópicamente antes de aplicar el ácido acético sugiriendo que así se ve más fácilmente el patrón vascular. Otros favorecen la aplicación de ácido acético únicamente y creen que el patrón vascular 
se aumenta por la observación colposcopica cuidadosa cuando el epitelio acetoblanco contrasta con los vasos negros (con filtro verde) sobre el fondo blanco. El éxito para detectar lesiones NIC-1 tempranas, más sutiles, es estar seguro que se ha producido un efecto completamente desarrollado de ácido acético. Esto se obtiene aplicando ácido acético al cervix antes de colocar el colposcopio y luego repitiendo la aplicación de la zona de transformación bajo control colposcópico. Sin un efecto bien desarrollado de ácido acético, es virtualmente imposible hacer una colposcopia adecuada (34).

El colposcopio debe usarse para delimitar la extensión completa de la lesión que el clínico debe biopsiar. Cuando se toman múltiples biopsias que comprenden toda el área anormal y cuando se toman muestras seleccionadas de las áreas que se piensa son benignas, entonces el efecto diagnóstico puede ser el mismo que el de la conización diagnóstica,pues la calidad y cantidad de tejido para examen histológico puede ser el mismo en ambos casos. Con cuidado, experiencia y atención meticulosa al curetaje endocervical y al muestreo del área colposcópicamente atípica, puede ser posible obtener el mismo grado de precisión diagnóstica con una aproximación ambulatoria dirigida colposcópicamente que con la conización intrahospitalaria (34).

\section{Curetaje endocervical}

\section{a. Indicaciones}

El curetaje endocervical (CEC) debe hacerse de rutina en pacientes que se estudian por frotis de Papanicolaou anormales a menos que estén embarazadas. Se puede hacer rápidamente, produce molestias cortas y no tiene morbilidad ni es costoso. El CEC es crítico para distinguir pacientes en riesgo de tener cáncer invasivo, las que no están en riesgo, documenta si el canal es negativo como el colposcopista piensa por su examen y detecta neoplasias del epitelio endocervical si las hay o neoplasia escamosa si la impresión colposcópica fue errónea. El estudio de errores diagnósticos entre pacientes con cáncer invasivo que fue equivocado con el colposcopio sugiere que la tasa de error colposcópico en la evaluación del canal endocervical es lo suficientemente grande como para recomendar el CEC como un procedimiento de rutina.

Si se detecta epitelio neoplásico con el CEC, es obligatoria una conización diagnóstica a menos que el colposcopista sea altamente entrenado y con experiencia y crea que el epitelio anormal se derivó de una lesión de la portio y no de compromiso verdadero de canal. En tales casos se recomienda una interconsulta $y$ un nuevo set de CEC negativo para estar seguro que no hay compromiso del canal. En la paciente embarazada no se recomienda el CEC de rutina por el riesgo de lesionar los productos de la concepción, pero son importantes las biopsias de áreas anormales para confirmar la impresión colposcópica.

\section{b. Interpretación}

Hay cuatro posibles diagnósticos del curetaje endocervical (34):

1) Insuficiente para diagnóstico. Cuando el espécimen consta de sangre y restos inflamatorios o el número de glándulas endocervicales es muy escaso.

2) Fragmentos de endocervix negativos. El espécimen es adecuado y no hay tejido neoplásico en el canal. 
3) Bandas de epitelio neoplásico. Se encuentran fragmentos de epitelio neoplásico (con características de NIC). Generalmente no es posible distinguir fácilmente entre NIC-1, 2 y 3 ni aún entre NIC y cáncer invasivo cuando solamente se tomó epitelio superficial con la cureta pues la orientación de los especímenes es al azar en los curetajes y es difícil de saber el plano de sección. Es infrecuente tener NIC- 1 en un CEC a menos que se haya tomado de una lesión de la portio con la cureta. Si el canal parece negativo colposcópicamente y se informa NIC-1 en el CEC se debe revisar el espécimen para asegurarse que realmente es: NIC -1 en el canal; no rara vez se encuentra que es metaplasia escamosa.

4) Cáncer invasivo. Es infrecuente ser capáz de hacer el diagnóstico de carcino$\mathrm{ma}$ invasivo de células escamosas en un CEC si la lesión es pequeña,pues la cureta rara vez penetra en el estroma en el que ocurre la invasión. En las lesiones grandes en forma de barril, el cáncer invasivo se puede diagnosticar frecuentemente con el CEC, pues la lesión tiende a ser necrótica y friable. También se pueden sospechar o diagnosticar fácilmente por CEC adenocarcinomas endocervicales o adenocarcinomas in situ.

\section{Biopsias cervicales}

Para tomar biopsias son más útiles las pinzas más pequeñas, tales como la de Kevorkian, que toman solamente milímetros y son altamente aceptables para la paciente. Las biopsias cervicales -que deben ser dirigidas colposcópicamentese orientan mejor para los cortes histológicos si el médico los coloca sobre una superficie plana cuando las toma y luego las coloca en el fijador de tal manera que se adhieran a la superficie. La orientación preferible es con el plano del epitelio perpendicular al plano del papel sobre el cual deben colocarse. Cuando se colocan en solución de Bouin las biopsias se adhieren generalmente al papel, pero se debe tener más cuidado cuando se usa formol como fijador. La solución de Bouin es preferible para pequeños especímenes de biopsia por ser un excelente preservativo citológico (34).

\section{Conización cervical}

\section{a. Ventajas y desventajas}

En el pasado la conización cervical se usó como la modalidad diagnóstica primaria ante un frotis de Papanicolaou anormal. Sus ventajas están en la capacidad del cirujano para remover una gran porción de tejido que generalmentecontiene las áreas más importantes para el diagnóstico y en la capacidad del patólogo para examinar virtualmente toda la zona de transformación y el canal endocervical para descartar la presencia de cáncer invasivo. Las desventajas son que requiere anestesia general, una hospitalización costosa y que el $15 \%$ de las pacientes sufre complicaciones significativas después del procedimiento. Para ser efectiva, el patólogo debe abrir el espécimen fresco, fijarlo abierto con alfileres y tomar secciones paralelas a intervalos de 2-3 $\mathrm{mm}$ en todo el espécimen. En circunstancias ideales no se debe equivocar un cáncer invasivo en ningún espécimen de conización, pero la conización no siempre es un procedimiento simple y el cirujano puede fallar en remover áreas claves. Además si el patólogo no examina todo el espécimen sino sólo cortes representativos, se puede errar un cáncer invasivo.

\section{b. Indicaciones}

Una variedad de criterios asiste al colposcopista para decidir cuáles pacientes, 
requieren conización y cuáles se pueden diagnosticar ambulatoriamente; éstos criterios son (34):

1) No se puede ver lesión. Se piensa que la enfermedad está en el canal. Esta situación ocurre principalmente en las pacientes más viejas en quienes la zona de transformación de la portio no existe o es completamente madura. Tales pacientes generalmente tienen un canal estrecho, difícil o imposible de visualizar. A menos que se vean los límites de la lesión, es imposible descartar cáncer invasivo. Estas pacientes se manejan con CEC para determinar que la lesión está en el canal, que las células anormales no provienen de otro sitio (vagina o vulva) y para establecer que no hay cáncer invasivo en el canal. Si el CEC tiene bandas de epitelio neoplásico pero no se puede hacer el diagnóstico de invasión, entonces la elección es la conización que puede ser tanto de carácter diagnóstico como terapéutico.

2) Se ve anornalidad colposcópica pero no se ven los limites de la lesión. Esto ocurre principalmente en pacientes con lesiones de mayor grado (NIC-2 y 3), cuyo epitelio anormal se extiende tanto en el canal endocervical que está más allá de la profundidad de la visualización usando el espéculo endocervical. En éstos casos se requiere la conización para descartar el cáncer invasivo y puede ser además terapéutica. La mayor indicación diagnóstica para el cono biopsia es el resultado inadecuado en el examen colposcópico (no se puede visualizar toda la zona de transformación) (36).

3) Citologia consistente con CA invasivo pero éste no se confirma con el exámen histológico. Si el citólogo cree que hay cáncer invasivo y éste no se detecta con examen colposcópico, biopsias cervicales y CEC, entonces se requiere la conización diagnóstica.

4) Impresión colposcópica de $C A$ invasivo que no se confirma histológicamente. Es preferible llevar a cabo un procedimiento diagnóstico adicional que asumir que las biopsias eran representativas y que la impresión colposcópica fue un error.

\section{5) Se diagnostica microinvasión en} una biopsia. Aunque es posible hacer un diagnóstico de carcinoma escamocelular invasivo en una biopsia, es difícil distinguir entre microinvasión e invasión franca basado exclusivamente en una biopsia. Si se informa microinvasión en una biopsia o en un CEC entonces se requiere una conización diagnóstica para determinar la extensión y profundidad de penetración de un foco invasivo y distinguir entre microinvasión y cáncer invasivo.

6) La paciente con la entidad no es confiable. Es obligación de la paciente que se maneje ambulatoriamente, adherirse al régimen de seguimiento propuesto por su médico. Se sugiere que las pacientes que no son buenas candidatas para el seguimiento se traten quirúrgicamente pues se piensa que ésta aproximación es más definitiva que los protocolos de manejo ambulatorio si no se adhieren al seguimiento prolongado.

7) Inexperiencia en colposcopia. Las pacientes con cáncer invasivo pueden tener en su mayor parte lesiones bien grandes y complejas y el colposcopista inexperto debería mejor pensar en obtener una conización en aquellas pacientes con lesiones grandes y complejas 
8) CEC positivo: Este es indicación de conización pues, desde el punto de vista diagnóstico, rara vez es posible graduar la severidad de la NIC o eliminar la posibilidad de un CA invasivo en fragmentos de CEC y, desde el punto de vista terapéutico, las lesiones que comprometen el canal endocervical no se pueden tratar bien con crioterapia o laser (36).

9) No es posible la colposcopia: La biopsia por conización ofrece una técnica satisfactoria para el diagnóstico de la Neoplasia Cervical en pacientes con citología anormal y sin lesión visible (36).

\section{c. Complicaciones}

La hemorragia es la mayor complica ción del cono, la incidencia de hemorraǵia significativa está entre el 5 y el $10 \%$ y puede ocurrir inmediatamente se termina la operación, antes de la salida de la paciente o una semana o más después de la cirugía. La estenosis cervical ocurre en 2 a $3 \%$ de pacientes y puede tratarse con dilataciones. También ocurre, con baja frecuencia, infección, perforación uterina y lesión a la vagina o el recto. El punto de la fertilidad es discutido pero parece que no hay evidencia que sugiera que la fertilidad o la tasa de aborto espontáneo temprano sean afectadas por el cono. La tasa de parto prematuro parece aumentar al aumentar el tejido extirpado (36).

\section{TRATAMIENTO}

Son evidentes los patrones cambiantes de la neoplasia cervical. Tienen lugar comúnmente la identificación de pacientes jóvenes con NIC y deseosas de fertilidad futura, por lo cual se buscan los medios de evaluar y tratar adecuadamente las pacientes sin procedimientos quirúrgicos. Para el tratamiento de la NIC se dispone de: Coagulación diatérmica bipolar;
Coagulación térmica; Resección con asa diatérmica; Criocirugía; Electrocauterio; Cirugía con Laser; Resección quirúrgica convencional; Conización; Amputación del cervix e Histerectomía $(37,34,38$, 39). Los resultados de algunas de éstas técnicas se resumen a continuación.

\section{Criterios para tratamiento ambulatorio de la NIC}

Antes de elegir una paciente para tratamiento ambulatorio el médico debe evaluar cuidadosamente toda la información de que dispone y estar seguro que las piezas independientes de información que se han acumulado confirman una a otra. Se deben correlacionar el frotis de Pap, apariencia colposcópica y diagnósticos histológicos. La apariencia colposcópica del canal y el diagnóstico en el CEC deben concordar. Si por alguna razón hay una sugerencia de cáncer invasivo en cualquiera de los datos acumulados antes del tratamiento, la paciente deberá someterse a la conización diagnósticà (34). Popkin resumió los criterios para tratamiento ambulatorio de la NIC así: (33).

a. Estudio colposcópico de toda la lesión y la zona de transformación.

b. Biopsia dirigida con colposcopia, que revela NIC.

c. Curetaje endocervical negativo.

d. Consentimiento de la paciente y seguridad de seguimiento a largo plazo.

e. Ausencia de hallazgos patológicos ginecológicos significativos que pueden hacer más apropiado el manejo quirúrgico. 
f. Buena correlación entre los hallazgos citológicos, colposcópicos e histológicos.

g. Ausencia de embarazo.

\section{Métodos de tratamiento}

\section{a. Crioterapia}

La aproximación terapéutica más simple y menos costosa en una paciente candidata para manejo ambulatorio es la crioterapia. La mayoría de los investigadores experimentados tiene una tasa de fallas de aproximadamente $12 \%$ cuando se acumulan todas las lesiones NIC, ésta proporción no parece diferir si se usa una técnica de congelado único o doble. La proporción de fallas depende del tamaño de la lesión y de la experiencia del investigador. El tiempo del procedimiento es de poco valor; el criterio para adecuación terapéutica es que la esfera del hielo se extienda 4-5 $\mathrm{mm}$ del borde de la lesión, en una lesión pequeña o mediana ésto requerirá generalmente sólo una aplicación. En lesiones más grandes pueden ser necesarias múltiples aplicaciones. Como la crioterapia es un procedimiento simple, seguro, sin morbilidad y barato, parece racional que sea la primera elección en un protocolo de manejo ambulatorio con la posibilidad que las pacientes con falla puedan ser tratadas con crioterapia o con otro procedimiento (34). La crioterapia fue el método de ablación local más comúnmente usado en los 1970 s y los resultados más recientemente publicados mostraron alrededor del $80 \%$ de efectividad para lesiones NIC-3 (40).

1) Ventajas. Es un método simple, de bajos costos, con gran aceptabilidad para la paciente y el médico y virtualmente carente de complicaciones. Puede evitar el cono en más del $70 \%$ de pacientes y el éxito de los embarazos futuros no se modifica ocurriendo una tasa de pérdida fetal similar a la de la población general (41).

2) Problemas. En la serie de Monaghan sólo dos de 204 pacientes reportaron complicaciones: una presentó pérdida menstrual abundante y otra infección urinaria severa (41). Las lesiones que se extienden al endocervix son difíciles de tratar (40).

3) Resultados. En la tabla No. 1 se presentan datos colectivos de eficacia $y$ de fallas con la criocirugía.

\section{b. Electrocauterio - Electrocoagulación diatérmica}

Los resultados con la técnica de electrocauterio son similares a los de crioterapia pero el electrocauterio es una técnica difícil de aplicar uniformemente, es dolorosa cuando se hace ambulatoriamente sin anestesia y produce estenosis cervical particularmente en las mujeres más viejas (34). La electrocoagulación diatérmica requliere anestesia general pero es una técnica precisa y segura (40). La tabla No. 2 reproduce algunos resultados con estas técnicas.

\section{c. Láser}

El láser de dióxido de carbono, destinado inicialmente a las comunicaciones, se usó por primera vez en cirugía ginecológica en 1974. El Láser puede usarse para vaporización o corte (conización). Para vaporización, la paciente debe llenar los siguientes criterios (42): Identificación colposcópica de toda la extensión de la lesión (márgenes normales ectocervical y endocervical); biopsia dirigida diagnóstica de enfermedad intraepitelial y CEC 
TABLA No. 1

\section{NIC TRATAMIENTO CON CRIOCIRUGIA}

\begin{tabular}{|c|c|c|c|c|c|c|c|}
\hline Autor, año, (ref) & Diagnóst & "Casos & Técnica & $\begin{array}{l}\text { Eficacia } \\
\%\end{array}$ & $\begin{array}{c}\text { Follas } \\
\%\end{array}$ & Recurrencia & Comentario \\
\hline $\begin{array}{l}\text { Coney, } 1983 \\
(43)\end{array}$ & $\mathrm{CIN}-1$ & 240 & $\begin{array}{l}\text { Unico- } \\
\text { Doble }\end{array}$ & $90 \%$ & $10 \%$ & & $\begin{array}{l}\text { Antes de } 1975 \text { congelado único en } \\
50 \% \text { de ptes, luego doble conge- } \\
\text { lado. Con retratamiento las fallas } \\
\text { disninuyeron a } 3 \% \text {. }\end{array}$ \\
\hline Kaufman, $1978(44$ & $\mathrm{CIN}-1$ & 66 & & 87.9 & 12.1 & & \multirow{3}{*}{$\begin{array}{l}\text { Mencionados por Coney (43) } \\
\text { Pranedio de falla } 11.8 \%\end{array}$} \\
\hline Saidi, $1977,(45)$ & " & 31 & & 90.3 & 9.7 & & \\
\hline Tredway, 1972 (46) & " & 30 & & 86.7 & 13.3 & & \\
\hline $\begin{array}{l}\text { Monaghan, } 1982 \\
\text { (41) }\end{array}$ & $\begin{array}{l}1-2 \\
D S \\
C I S\end{array}$ & $\begin{array}{l}49 \\
44 \\
65\end{array}$ & $\begin{array}{l}\text { Doble } \\
\mathrm{NO}_{2}\end{array}$ & & $\begin{array}{r}8 \\
18 \\
12\end{array}$ & & $\begin{array}{l}\text { Exito }=\text { CCV }(-) \text { al año. En total } \\
\text { de las } 109 \text { casos de } C I N-3 \text { hubo } \\
16(15 \%) \text { de fallas. }\end{array}$ \\
\hline Singer $1982(40)$ & & & & 80 & & & \\
\hline Varios 1981 & $1-3$ & & & & 12 & & \multirow{3}{*}{$\begin{array}{l}\text { Mencionados por Richart (34) } \\
\text { Mencionados por Creasman (39) }\end{array}$} \\
\hline Popkin $1978(4 \%)$ & 1 & 57 & & & 0 & & \\
\hline & $\begin{array}{l}2 \\
3\end{array}$ & $\begin{array}{l}76 \\
75\end{array}$ & & & $\begin{array}{l}5 \\
1\end{array}$ & & \\
\hline $\begin{array}{l}\text { Townsend } 1979 \\
\text { (48) }\end{array}$ & $\begin{array}{l}1 \\
2 \\
3\end{array}$ & $\begin{array}{l}250 \\
250 \\
250\end{array}$ & Unico & & $\begin{array}{l}5 \\
11 \\
16\end{array}$ & & \multirow[t]{3}{*}{$\begin{array}{cc}\text { Falla con retratamiento: } & 0 \% \\
" 1 & 3 \% \\
" & 7 \%\end{array}$} \\
\hline $\begin{array}{l}\text { Kaufman } 1978 \\
(49)\end{array}$ & $\begin{array}{l}1 \\
2 \\
3\end{array}$ & $\begin{array}{r}66 \\
142 \\
187\end{array}$ & & & $\begin{array}{l}12 \\
4 \\
16\end{array}$ & & \\
\hline $\begin{array}{l}\text { Creasman } 1973 \\
(50)\end{array}$ & $\begin{array}{l}1 \\
2 \\
3\end{array}$ & $\begin{array}{l}134 \\
145 \\
278\end{array}$ & Doble & & $\begin{array}{l}9 \\
5 \\
12\end{array}$ & & \\
\hline $\begin{array}{l}\text { Richart } 1980 \\
(51)\end{array}$ & $\begin{array}{l}1 \\
2 \\
3\end{array}$ & $\begin{array}{l}898 \\
977 \\
964 \\
\end{array}$ & & & & $\begin{array}{l}\text { Total } 19 \\
\text { cosos } \\
0.44^{\circ} \\
\end{array}$ & $\begin{array}{l}\text { Casi la mitad son persistencio } \\
\text { de la enfemedad y no verdade- } \\
\text { a resurencio. }\end{array}$ \\
\hline
\end{tabular}

TABLA No. 2

NIC TRATAMIENTO CON ELECTROCAUTERIO ELECTROCOAGULACION DIATERMICA

\begin{tabular}{|c|c|c|c|c|c|c|}
\hline Autor, año, (ref) & Diagnost & ${ }^{\#}$ Cosos & Técnica & Eficacia & Falkas \% & Comentarios \\
\hline $\begin{array}{l}\text { Richart } 1968 \\
(52)\end{array}$ & $\begin{array}{c}\text { CIN-1 } \\
2 \\
3\end{array}$ & $\begin{array}{r}114 \\
51 \\
5\end{array}$ & $\begin{array}{l}\text { solo } 1 \text { tho } \\
\text { cauterio }\end{array}$ & & $\begin{array}{c}12 \\
6 \\
40\end{array}$ & \multirow{4}{*}{$\begin{array}{l}\text { Mencionados por Creasman }(\overline{39}) \overline{ } \\
\text { Aproximadamente la mitad tenían CIN3 }\end{array}$} \\
\hline Ortíz 1973 (53) & $\begin{array}{l}1 \\
2 \\
3\end{array}$ & $\begin{array}{c}18 \\
42 \\
88 \\
\end{array}$ & cauterio & & $\begin{array}{r}0 \\
0 \\
14\end{array}$ & \\
\hline $\begin{array}{l}\text { Hollyock } 1976 \\
(54)\end{array}$ & $\begin{array}{l}1 \\
2 \\
3\end{array}$ & $\begin{array}{l}130 \\
111 \\
197\end{array}$ & Diatermia & & $\begin{array}{l}8 \\
5 \\
5\end{array}$ & \\
\hline $\begin{array}{l}\text { Chanen } 1979 \\
(55)\end{array}$ & $1-3$ & 812 & " & $95 \%$ & & \\
\hline $\begin{array}{l}\text { Chanen } 1982 \\
(56)\end{array}$ & $1-3$ & 1500 & 11 & $96.5 \%$ & & $\begin{array}{l}\text { 14 años de Tto. Mencionado por } \\
\text { Singer }(40)\end{array}$ \\
\hline
\end{tabular}

y confirmación endoscópica que la NIC no se extiende al canal. Los criterios para el cono incisional con laser son: NIC que se extiende al endocervix, patología que sugiere invasión estromal, discordancia entre el frotis de Pap y la biopsia y colposcopia insatisfactoria (42). 
1) Ventajas. La evaporación puede hacerse sin anestesia ni aralgesia y sólo un $20 \%$ de pacientes experimentan molestia moderada o leve durante 5 ó $10 \mathrm{mi}-$ nutos del procedimiento. Se puede controlar y medir con precisión la profundidad de la destrucción tisular, así que se pueden tratar las criptas profundas comprometidas. La curación de los tejidos es muy rápida y superior a la que se produce por la crioterapia o la electrocoagulación diatérmica en las que ocurre necrosis de los tejidos sanos adyacentes, el tratamiento con laser lleva a un cervix remodelado en el que es accesible el canal endocervical y cualquier recurrencia puede verse fácilmente con el colposcopio. El láser es seguro si se toman algunas precauciones y la recurrencia es baja considerando la profundidad y destrucción completa $(33,40)$. Las mayores ventajas de la conización con láser son la precisión del control microscópico, la excelente hemostasia obtenida y la carencia de material de sutura en la herida que reduce el riesgo de estenosis y de infertilidad subsecuente (42)
2) Complicaciones y problemas. La mayoría de pacientes describen inicialmente una sensación de punzada, luego - cuando el laser dura largos períodossensación de calor y cuando se vaporiza una gran porción de tejido se producen calambres semejantes a los de la dismenorrea. Puede ocurrir hemorragia menor en la mayoría de pacientes una o dos semanas después de la vaporización, que cede espontáneamente. También se ha observado flujo menstrual abundante. Con la conización puede ocurrir hemorragia durante o después de la terapia y estenosis cervical en muy pocos ca$\operatorname{sos}(42)$.

3) Resultados. En la tabla No. 3 se resumen los resultados para el laser de bióxido de carbono.

\section{d. "Cold coagulator"}

El "Cold coagulator" de Semm actúa a temperatura alta produciendo coagulación calórica al contrario de lo que el nombre sugiere. Los criterios de selección son semejantes a los de otros tratamien tos ambulatorios.

TABLA No. 3

NIC TRATAMIENTO CON LASER DE $\mathrm{CO}_{2}$

\begin{tabular}{|c|c|c|c|c|c|c|}
\hline Autor, año, (ref) & Diagnost & Casos & Téonica & Curación\% & Falla\% & Comentarios \\
\hline Popkin 1983 (33) & $\begin{array}{c}\text { CॉN-1 } \\
2 \\
3 \\
\end{array}$ & $\begin{array}{c}26 \\
82 \\
30 \\
\end{array}$ & $\begin{array}{l}\text { Voporiza- } \\
\text { ción, } 1 \\
\text { vez }\end{array}$ & & $\begin{array}{c}11 \\
8.5 \\
10\end{array}$ & $\begin{array}{l}\text { Los pacientes de falla }(13 \text { casos) se } \\
\text { encontraron en } 7 \text { meses y se retrata- } \\
\text { ron con laser o conización. }\end{array}$ \\
\hline Boggish $1983(42)$ & $\begin{array}{l}1 \\
2 \\
3\end{array}$ & $\begin{array}{l}89 \\
143 \\
182\end{array}$ & $\begin{array}{l}\text { Vaporiza- } \\
\text { ción, re- } \\
\text { tto. }\end{array}$ & $\begin{array}{r}100 \\
194 \\
95\end{array}$ & $\begin{array}{l}0 \\
6 \\
5\end{array}$ & \\
\hline Baggish 1983 (42) & $\begin{array}{l} \\
2 \\
3\end{array}$ & $\begin{array}{c}5 \\
35 \\
55\end{array}$ & Cono & & $\begin{array}{l}0 \\
1 \\
2\end{array}$ & $\begin{array}{l}\text { Falla = con margen endocervical o ecto- } \\
\text { cervical positico. }\end{array}$ \\
\hline Evans-Monaghan & $\overline{C I N}$ & 408 & $\begin{array}{l}\text { Vapori- } \\
\text { zación }\end{array}$ & 97 & & $\begin{array}{l}30 \text { casos recibierob } 2 \text { thos. (tasa de cu- } \\
\text { ración primaria del } 90 \% \text { ). Mencionado } \\
\text { por Baggish (42) }\end{array}$ \\
\hline Wright-Davies & 3 & 131 & & 92,3 & 7.7 & \\
\hline Byron 198| (57) & $\begin{array}{l}1 \\
2 \\
3 \\
\mathrm{C} 15\end{array}$ & $\begin{array}{r}38 \\
104 \\
56 \\
62\end{array}$ & & & $\begin{array}{l}\text { Total } \\
18\end{array}$ & $\begin{array}{l}\text { Experiencio de } 5 \text { años. El } 97 \% \text { de las } \\
\text { fallas oourrieron cuando se usó penetra- } \\
\text { ción de } 3 \mathrm{~mm} \text { y bajo poder de densidad } \\
\text { Mas efectivo con remo*ión de } Z \mathrm{~mm} \text { y } \\
\text { densidad mayor de } 2000 \mathrm{~W} / \mathrm{cm}^{2} \text {. }\end{array}$ \\
\hline Burke $1980(58)$ & $\begin{array}{l}1 \\
2 \\
3\end{array}$ & $\begin{array}{l}21 \\
19 \\
20\end{array}$ & $"$ & & $\begin{array}{l}28 \\
58 \\
25\end{array}$ & Mencionodos por Creasman (39) \\
\hline Baggish $1980 \quad(59$ & $\begin{array}{l}1 \\
2 \\
3\end{array}$ & $\begin{array}{l}25 \\
43 \\
47\end{array}$ & & & $\begin{array}{r}20 \\
30 \\
32\end{array}$ & \\
\hline
\end{tabular}


1) Ventajas. El procedimiento es tan corto que la molestia es tolerable para la mayoría de las pacientes haciendo innecesaria la anestesia. Su operación es silente y carece de contaminación y olor. El costo del instrumento es similar al de de criocirugía y es fácil de transportar. Su efectividad es comparable a la de otras técnicas destructivas: Se pueden tratar lesiones de diferente tamaño y repetir el tratamiento si es necesario. Puede utilizarse para otras lesiones cervicales benignas y para neoplasia intraepitelial vaginal y vulvar. La hemorragia y flujo postoperatorios no son un problema en la mayoría de pacientes y no afecta la fertilidad ni el curso del embarazo (60).

2) Complicaciones y problemas. Las termosondas no se pueden reparar. Ocurrió hemorragia persistente por una a seis semanas en $3.5 \%$ de los casos pero no requirió generalmente ningún tratamiento. El $1 \%$ de pacientes se quejan de dolor pélvico persistente que puede desaparecer sin ningún tratamiento y ocurrió un caso de episodio vasovagal. $1 \%$ de pacientes tuvieron estenosis cervical que requirió dilatación (60).

3) Resultados. Se resumen en la tabla No. 4.

\section{e. Conización - Histerectomia}

Las indicaciones del cono diagnóstico ya fueron enumeradas en la segunda parte de ésta revisión y se mencionaron los casos en los cuales el procedimiento era además terapéutico. El cona terapéutico también está indicado en los casos de NIC-3 si la lesión es muy grande y cuando es problemático el seguimiento del paciente (36). Hay una tasa de morbilidad significativa después del cono que incluye: hemorragia, infección, estenosis cervical y riesgo de parto prematuro (3.4 veces mayor) así como riesgo de bajo peso al nacer (2.5 veces may or).

En el momento parece que al menos tres cuartas partes de las mujeres jóvenes con NIC-3 son candidatas para uno de los procedimientos destructivos locales, pero se mantienen varias indicaciones del cono (40). Andersch et. al., (61) encontraron en 429 mujeres con CIS, durante un tiempo de seguimiento de diez años, una frecuencia de recaídas de 5.3\%; la conización fue el tratamiento primario en 414 casos, en 13 casos la histerectomía $y$ en 2 casos la radioterapia.

En la literatura se reporta alrededor del $30 \%$ de incidencia de márgenes posi-

TABLA No. 4

\section{NIC TRATAMIENTO CON COLD COAGULATOR}

\begin{tabular}{|c|c|c|c|c|c|}
\hline Autor, año, (ref) & Diagnost & \#Casos & Eficacia & Fallas \% & Comentarios \\
\hline Duncan $1983(60)$ & $\begin{array}{c}\text { CIN-1 } \\
2 \\
\text { DS } \\
\text { CIS }\end{array}$ & $\begin{array}{r}86 \\
101 \\
99 \\
306\end{array}$ & & $\begin{array}{l}2.5 \% \\
1 \% \\
1 \% \\
3.6 \%\end{array}$ & 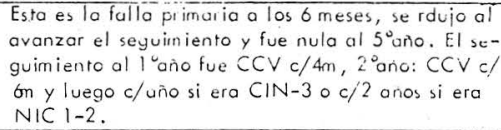 \\
\hline Duncan $1982(t 2)$ & 3 & & $95 \%$ & & Mencionade por Singer 140 \\
\hline Duncan 1981 & $\begin{array}{l}1 \\
2 \\
3\end{array}$ & $\begin{array}{r}36 \\
33 \\
144\end{array}$ & & $\begin{array}{l}5 \% \\
6 \% \\
5 \%\end{array}$ & Mencionado por Creasman (39) \\
\hline
\end{tabular}

DS: displasia severa

CIS: Carcinomo in situ 
tivas del cono. En una serie el $16 \%$ de pacientes que fueron histerectomizadas tenían NIC residual después de un cono con márgenes negativos, lo cual enfatiza la importancia del número de secciones examinadas en el cono. Se ha reportado que un $5 \%$ de pacientes con NIC en los bordes del cono tuvieron citología anormal en la visita de seguimiento posterior. La mayoría de éstas pacientes tuvieron citología o colposcopia positiva dentro de los primeros seis meses después del cono, sugiriendo lesión persistente más que recurrente. Cuando se consideraron todas las pacientes que tuvieron frotis negativos después de la conización para $\mathrm{CIS}$, solamente $0.5 \%$ desarrollaron lesión recurrente. En otra serie se reportó una recurrencia del $2.4 \%$ del $\mathrm{CIS}$, pero dos tercios se diagnosticaron en los dos primeros años después del cono inicial sugiriendo nuevamente persistencia más que recurrencia de la lesión. Se han encontrado la mayoría de las recurrencias de las lesiones in situ entre 2-3 años, pero un caso se diagnosticó diez años después del cono inicial y se ha encontra- do también CA invasivo entre 3-9 años después del cono (36). La tabla No. 5 reune algunos de los resultados del cono e histerectomía en el manejo de la NIC.

\section{MATERIALES Y METODOS}

\section{A. TIPO DE ESTUDIO}

Este es un estudio retrospectivo y descriptivo basado en la revisión de Historias Clínicas e informes de Anatomía Patológica.

\section{B. POBLACION DE ESTUDIO}

Las pacientes que forman parte del estudio tuvieron el diagnóstico anatomopatológico de Neoplasia Intraepitelial Cervical y consultaron a la clínica de tumores del Hospital Materno Infantil de Bogotá en el lapso de cinco años comprendido entre el 1o. de enero de 1978 y el 31 de diciembre de 1982. Tales pacientes son remitidas de los Centros cie Salud del área de influencia del Hospital, y pertenecen a un nivel socioeconómico bajo.

TABLA No. 5

COMPARACION DE LA RECURRENCIA EN EL SEGUIMIENTO DE PACIENTES TRATADAS CON CONO O HISTERECTOMIA PARA CA IN SITU (NIC-3)

\begin{tabular}{|c|c|c|c|c|c|c|c|}
\hline Autor, año, (ref) & & Cono & & Histe & rectom & & Cbservaciones \\
\hline & 7 Pocient. & $\mathrm{C} 15 \%$ & ¡nvasión\% & \#Pacient. & CIS\% & invasión is & \\
\hline Boyes 1970 & 808 & 3.4 & 0.4 & 2849 & 0.7 & 0.1 & \\
\hline Creasman 1972 & & & & 642 & 1.5 & 0.5 & \\
\hline Bjerre 1972 & 1430 & 8.9 & 0.5 & & & & \\
\hline Kolstad $1976(63)$ & 795 & 2.4 & 0.9 & 238 & 1.3 & 2.1 & \\
\hline Barros 1980 & $19^{\prime}$ & $(7) 36 \%$ & & & & & \\
\hline Bughardtt 1980 & 1219 & $40 \%{ }^{\star}$ & & & & & *Epitelio an_rmal al margen \\
\hline Benedet 1982 & 966 & $25 \%+$ & & & & & + Displosia o CIS al margen \\
\hline $\begin{array}{l}\text { Varios 1970- } \\
1976,1978\end{array}$ & 3000 & $6 \%$ & $0.6 \%$ & & & & $\begin{array}{l}\text { Mencionodos por Creasman } \\
\text { (39) }\end{array}$ \\
\hline
\end{tabular}


El criterio para incluir las pacientes fue la confirmación histológica en la biopsia o en la pieza quirúrgica de Neoplasia Intraepitelial Cervical (NIC-1 = Displasia leve, NIC-2 = Displasia moderada y $\mathrm{NIC}-3=$ Displasia severa o carcinoma in situ). Los criterios histológico y colposcópico requirieron confirmación histológica.

\section{RECOLECCION}

\section{Técnica}

Consultando los registros de los informes de anatomía patológica del Departamento de Patología del hospital, se obtuvieron los números de las Historias Clínicas y/o los nombres de las pacientes con el diagnóstico de Neoplasia Intraepitelial Cervical. Posteriormente se consultaron las Historias Clínicas en el archivo de estadística para la obtención de los datos.

\section{Instrumento de recolección}

Se diseñó un formulario precodificado para consignar los datos de las pacientes investigando los siguientes conceptos y variables. (Se anexa el formulario No. 1).

\section{a. Edad. Variable: años.}

b. Motivo de consulta. Variables: Consulta de rutina; dolor pélvico; flujo vaginal; metrorragia; embarazo; otros.

c. Historia Gineco-obstétrica. Variables: gestaciones; partos; tipo de parto, edad de la primera relación sexual, número de compañeros sexuales, método de anticoncepción.

d. Patología cervical previa. Variables: cervlcitis, pólipos, herpes, displasias. e. Tratamientos previos. Variables: médico, cauterización, conización, otros.

f. Citologia cérvico-vaginal.

g. Colposcopia

h. Informe de anatomia patológica. De la pieza quirúrgica terapéutica y de las muestras diagnósticas. Variables: cervicitis, displasias, carcinoma in situ, carcinoma infiltrante.

i. Estudio de la pieza quirirgica. Variable: número de cuadrantes positivos.

j. Tratamientos. Variables: médico, electrocauterio, conización, histerectomía abdominal ampliada.

k. Fallas del tratamiento. Variables: persistencia, recidiva.

\section{l. Curación}

\section{PROCESAMIENTO}

\section{Técnica}

Se procesaron con el computador con base en el formulario precodificado.

\section{Análisis}

Se analizaron proporciones porcentuales y se compararon categorías equivalentes. El período de tiempo estudiado se escogió para tener a la fecha de realización del trabajo un seguimiento mínimo de cinco años de las pacientes.

\section{Presentación}

Los resultados se presentan en forma de tablas. 
FORMULARIO No. 1

NEOPLASIAS INTRAEPITELIALES DEL CERVIX

INSTITUCION

No. DE ORDEN

Ciudad

VOMBRE DEL PACIENTE

c.C.

H. CLINICA No.

EDAD

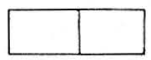

99

( ) $\sin \ln f$.

IV. NUMERO DE GESTACIONES

$0($ ) Ninguno

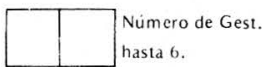

$8(1)$ Más de 7

9() Sin Inf.

VI. EDAD DEL PRIMER PARTO

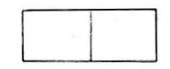

99 () $\sin \operatorname{Inf}$.

VIII. EDADINICIO DE RELACIONES

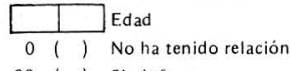

$99($ ) Sin inf.

X. ANTICONCEPCION

$\begin{array}{llll}0 & ( & \text { Ninguna } \\ 1 & ( & \text { DIU } \\ 2 & ( & \text { Hormonales } \\ 3 & ( & \text { Ovulos } \\ 4 & ( & \text { Condón } \\ 5 & ( & \text { Ligadura } \\ 6 & ( & \text { Otros: } \\ 9 & ( & \text { Sin Inf. }\end{array}$

II. MOTIVO DE CONSULTA

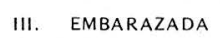

1 ( ) Flujo genital

$2($ ) Metrorragia

$3($ ) sangrado post-coito

$4($ ) Dolor pélvico

5 ( ) Examen de rutina

$6($ ) Otros:

9() Sin Inf.

V. NUMERO DE PARTOS

$$
0(\text { ) Ninguno }
$$

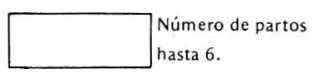

$$
\begin{aligned}
& 8(\text { ) Más de } 7 \\
& 9(\text { ) Sin Inf. }
\end{aligned}
$$

VII. TIPO DE PARTOS
O ( ) No aplica
1 ( ) Vaginal
2 ( ) Cesárea
3 ( ) Vaginales y cesáreas
9 ( ) Sin Inf.

IX. NUMERO DE COMPAÑEROS SEXUALES

$$
\begin{array}{lll}
0 & (\text { ) } & \text { Ninguno } \\
1 & (\text { ) } & \text { Uno } \\
2 & (\text { ) } & \text { Dos } \\
3 & (\text { ) } & \text { Tres } \\
4 & (\text { ) } & \text { Más de tres } \\
5 & (\text { ) } & \text { Prostitución } \\
9 & (\text { ) } & \text { Sin Inf. }
\end{array}
$$

XI. PATOLOGIA CERVICAL PREVIA

$$
\begin{aligned}
& 0 \text { ( ) Ninguna } \\
& 1 \text { ( ) Cervicitis } \\
& \text { 2. ( ) Pólipos cervicales } \\
& 3 \text { ( ) Herpes } \\
& 4 \text { ( ) Coilocitosis } \\
& 5 \text { ( ) Displasia leve } \\
& 6 \text { ( ) Displasia moderada } \\
& 7 \text { ( ) Displasia severa } \\
& 81 \text { ) Ca. In Situ } \\
& 91 \text { ) Sin Inf. }
\end{aligned}
$$

(Continúa) 
(Continuación)

XII. TRATAMIENTOS PREVIOS CERVIX

$\begin{array}{llll}0 & ( & \text { ) Ninguno } \\ 1 & ( & \text { Médico } \\ 2 & ( & \text { Cauterización } \\ 3 & (1) & \text { Criocirugía } \\ 4 & (\text { ) } & \text { Conizaclón } \\ 5 & (\text { ) Manchester-traquelectomia } \\ 6 & (\text { ) Otros: } \\ 9 & (\text { ) Sin Inf. }\end{array}$

XIV COLPOSCOPIA
0 ( ) No se hizo
$1($ ) Negativa
2 ( ) Sospechosa

XV. INFORME A.P. 1a. Serie

\begin{tabular}{|c|c|c|}
\hline Fecha & Mes & Año \\
\hline 1 & 11 & Cervicitis \\
\hline 2 & 11 & Displasia ligera \\
\hline 3 & 11 & Displasia moderada \\
\hline 4 & 11 & Displasia Severa \\
\hline 5 & 11 & CA. In Situ \\
\hline 6 & 11 & Otro (especifique): \\
\hline
\end{tabular}

XVII. INFORME A.P. 3a. Serie

\begin{tabular}{|c|c|c|}
\hline 0 & 1 & No se tomó \\
\hline 1 & 1 & Cervicitis \\
\hline & 1 & Displasia ligera \\
\hline & 1 & Displasia Moderada \\
\hline & 1 & Displasia Severa \\
\hline & 1 & CA. In Situ. \\
\hline & 1 & CA. Microinfiltrante \\
\hline & 1 & CA. Infiltrante \\
\hline & ) & Otro (especifique): \\
\hline
\end{tabular}

Fecha Mes $\square \square$ Año

XIX. INFORME A.P. UTERO

\begin{tabular}{|c|c|c|c|}
\hline Fecha & & Mes & Año \\
\hline 0 & 1 & ) & No se hizo Cirugia \\
\hline 1 & 1 & ) & Sin lesión residual \\
\hline 2 & 1 & ) & Cervicit is \\
\hline 3 & 1 & ) & Displasia ligera \\
\hline 4 & 1 & 1 & Displasia Moderada \\
\hline 5 & 1 & ) & Displasia Severa \\
\hline 6 & ( & ) & CA. In Situ. \\
\hline 7 & 1 & ) & CA. Microinfiltrante \\
\hline 8 & 1 & ) & CA. infiltrante \\
\hline
\end{tabular}

XIII CITOLOGIA

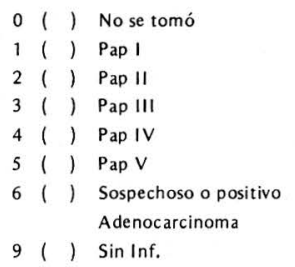

XVI. INFORME A.P. 2a. Serie

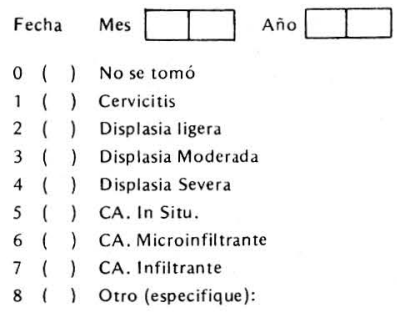

XVIII. INFORME A.P.. CONO

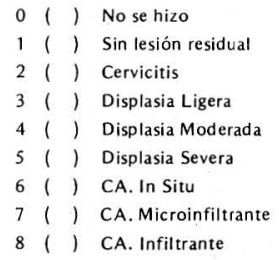

Fecha Mes Año

$X X$. ESTUDIO PIEZA QUIRURGICA CERVIX

$$
\begin{aligned}
& \text { (Número de cuadrantes positivos) } \\
& \text { o ( ) No se hizo Cirugía } \\
& 1 \text { ( ) Uno } \\
& 2 \text { ( ) Dos } \\
& 3(\text { ) Tres } \\
& 4 \text { ( ) Cuatro } \\
& 5 \text { ( ) Vértice } \\
& 9 \text { () Sin Inf. }
\end{aligned}
$$

(Continúa) 


\section{(Continuación)}

XXI. ESTUDIO PIEZA QUIRURGICA

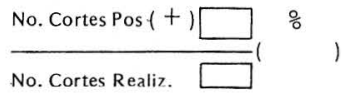

XXIII. COMPLICACIONES CONIZACION

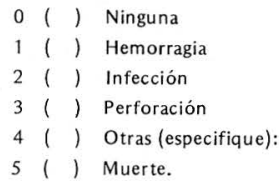

XXV. TRATAMIENTO INICIAL POST-DIAGNOSTICO

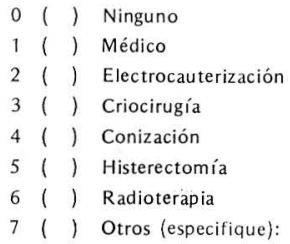

XXVIII. TIPO DE RECIDIVA

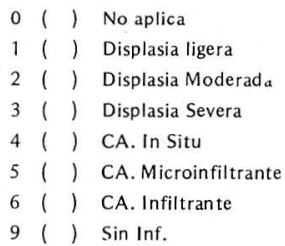

XXX. FECHA TRATAMIENTO RECIDIVA

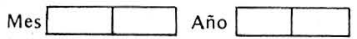

XXXI. FECHA ULTIMO CONTROL Mes Año

\begin{tabular}{|l|l|}
\hline & \\
\hline
\end{tabular}

\section{RESULTADOS}

\section{A. INCIDENCIA}

Se revisaron 32 historias clínicas de pacientes con diagnóstico histológico de NIC. Durante el período comprendido
XXII. FECHA TRATAMIENTO INICIAL

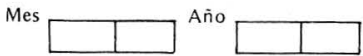

XXIV. COMPLICACIONES HISTERECTOM

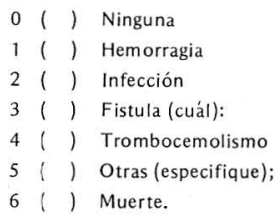

XXVI.PERSISTENCIA - RECIDIVA LESIC
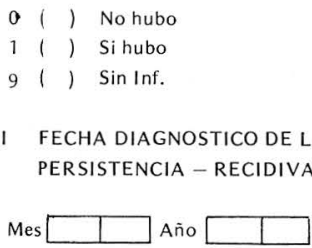

XXIX. TRATAMIENTO REALIZADO PERSISTENCIA - RECIDIVA.

0 ( ) Ningu no

1 ( ) Médico

2 ( ) Electro

3 ( ) Criocirugía

4 ( ) Conixación

5 ( ) Histerectomía

6 ( ) Radioterapia

7 ( ) Otros (especifique):

9 ( ) Sin Inf.

XXXII. ESTADO' AL ULTIMO CONTROL

$$
\begin{aligned}
& 1 \text { ( ) Pérdida } \\
& 2 \text { ( ) Sin evidencia Enf. } \\
& 3 \text { ( ) Con evidencia Enf. } \\
& 4 \text { ( ) Muerte } x \text { Enf. } \\
& 5(1) \text { Muerte otras causas. }
\end{aligned}
$$

entre el 1o. de enero de 1978 y el 31 de diciembre de 1982, la incidencia de CA invasivo del cérvix fue del 3.79 por mil (109 casos) y la de la NIC fue del 1.11 por mil (32 casos) en la consul ta ginecológica del Hospital Materno Infantil. La tabla No. 6 muestra la distribución por 
años de las pacientes que consultaron al servicio de ginecología, de las pacientes remitidas a especialidades (consulta a la cual pertenece la clínica de tumores) y la frecuencia del CA invasivo y la NIC demostrados histológicamente.

TABLA No. 6

DISTRIBUCION POR AÑOS DE LAS PACIENTES CON
CA INVASIVO Y NIC

\begin{tabular}{|l|r|r|r|r|r|r|r|}
\hline ESPEC IFICAC. & 1978 & 1979 & 1980 & 1981 & 1982 & TCTAL & $\begin{array}{l}\text { INCIDEN } \\
\text { CIA }\end{array}$ \\
\hline $\begin{array}{l}\text { Consulta Gineco- } \\
\text { lógica. }\end{array}$ & 6.607 & 3.166 & 5354 & 6.264 & 7.322 & $2 \varepsilon .713$ & \\
\hline $\begin{array}{l}\text { Consulta de espe- } \\
\text { cialidades }\end{array}$ & 1.687 & 843 & 1922 & 1.624 & 1.542 & 7.618 & \\
\hline $\begin{array}{l}\text { Cirugías ginecoló- } \\
\text { gicas }\end{array}$ & 599 & 339 & 294 & 358 & 524 & 2.114 & \\
\hline $\begin{array}{l}\text { CA invasivo del } \\
\text { cérvix }\end{array}$ & 39 & 29 & 24 & 11 & 6 & 109 & $3.79 \%$ \\
\hline NIC 1-3 & 18 & 3 & 11 & 0 & 0 & 32 & $1.11 \%$ \\
\hline
\end{tabular}

\section{B. EDAD}

Las edades de las pacientes estaban comprendidas entre los 25 y los 61 años, con un promedio de 39.7 años. La tabla No. 7 muestra la distribución por edades promedio para cada tipo de NIC diagnosticada en la primera serie de biopsias y la frecuencia relativa de cada tipo de NIC en este estudio

\section{MOTIVO DE CONSULTA}

La tabla No. 8 muestra la distribución de las pacientes según el motivo de consulta. El examen de rutina fue la forma más. frecuente de detectar la NIC (43.7응).
TABLA No. 7

DISTRIBUCION DE LAS PACIENTES CON NIC SEGUN LA EDAD

\begin{tabular}{|c|c|c|c|}
\hline IIPC DE NIC & " DE CASOS & $\%$ & EDAD PRCMEDIO \\
\hline NIC 1 & 7 & 21.8 & 42.4 \\
\hline NIC 2 & 5 & 15.6 & 38.4 \\
\hline IIC 3 & 19 & 59.3 & 37.4 \\
\hline DS & 6 & 18.7 & 32.0 \\
\hline CIS & 13 & 40.6 & 42.8 \\
\hline Sin biopsio inicial & 1 & 3.1 & 37.0 \\
\hline TGIAI & 3 & 100.0 & 37. \\
\hline
\end{tabular}

D. PARIDAD

La tabla No. 9 muestra el promedio de gestaciones y de partos para cada tipo de 
NIC. A excepción de dos pacientes (una primípara y otra nuligestante) todas las demás fueron multíparas; dichas pacientes presentaban ambas carcinoma in situ (CIS) del cervix.

TABLA No. 8

MOTIVOS DE CONSULTA DE LAS PACIENTES CON NIC

\begin{tabular}{|l|c|c|}
\hline MCTIVO DE CONSULTA & $\#$ & $\%$ \\
\hline Exámen de rutina & 14 & $43.7 \%$ \\
\hline Metrorragia & 10 & $31.2 \%$ \\
\hline Flujo vaginal & 2 & $6.2 \%$ \\
\hline Dolor pélvico & 1 & $3.1 \%$ \\
\hline Otros & 5 & $15.6 \%$ \\
\hline TOTAL & 32 & $100.0 \%$ \\
\hline
\end{tabular}

TABLA No. 9

\section{DISTRIBUCION DE LAS PACIENTES CON NIC SEGUN EL NUMERO DE GESTACIONES Y LA PARIDAD}

\begin{tabular}{|c|c|c|}
\hline TIPC DE NIC & $\begin{array}{c}\text { PROMEDIC DE } \\
\text { GES TAC IONES }\end{array}$ & $\begin{array}{c}\text { PROMEDIO DE } \\
\text { PARTCS }\end{array}$ \\
\hline NIC 1 & 6.2 & 5.5 \\
\hline NIC 2 & 5.2 & 5.0 \\
\hline NIC 3 & 5.8 & 4.9 \\
\hline DS & 6.0 & 3.8 \\
\hline CIS & 6.2 & 5.4 \\
\hline
\end{tabular}

E. EDAD DEL PRIMER PARTO Y DEL PRIMER COITO

La tabla No. 10 muestra los promedios de la edad del primer parto distribuidos para cada tipo de NIC; la edad del primer parto se consignó en 22 casos (72\%) mientras que la edad de la primera relación sexual solamente se consignó en 14 historias (43응 de los casos). Todos los datos se analizan en la cuarta sección del trabajo.

TABLA No. 10

EDAD DEL PRIMER PARTO

EN LAS PACIENTES CON NIC

\begin{tabular}{|c|c|}
\hline TIPO DE NIC & EDAD PRCMEDIO \\
\hline NIC 1 & 24.0 \\
\hline NIC 2 & 20.0 \\
\hline NIC 3 & 20.4 \\
\hline DS & 20.0 \\
\hline CIS & 20.6 \\
\hline
\end{tabular}

$\mathrm{DS}=$ Displasia severa

$\mathrm{CIS}=$ Carcinoma in situ

\section{F. COMPAÑEROS SEXUALES}

En 17 casos (53.7\%) no se consignó el número de compañeros sexuales y en todas las demás se registra un sólo compañero sexual.

\section{G. ANTICONCEPCION}

La tabla No. 11 consigna los métodos de anticoncepción; cuando se combina- 
ron varios métodos se trató en 3 casos de uno temporal (DIU, hormonal y condom) y, posteriormente, uno definitivo (ligadura de trompas) y en otro caso se trató de DIU y posteriormente anticoncepción hormonal. EI DIU fue el método más frecuentemente usado (34.3응).

TABLA No. 11

\section{METODOS DE ANTICONCEPCION EN LAS PACIENTES CON NIC}

\begin{tabular}{|l|c|c|}
\hline $\begin{array}{c}\text { METODO DE } \\
\text { ANTICONCEP. }\end{array}$ & $\#$ & $\%$ \\
\hline DIU & 11 & 34.3 \\
\hline Varios & 4 & 12.5 \\
\hline Ninguno & 4 & 12.5 \\
\hline Ligadura & 1 & 3.1 \\
\hline Sin informe & 12 & 37.5 \\
\hline TOTAL & 32 & 100.0 \\
\hline
\end{tabular}

\section{H. PATOLOGIA CERVICAL PREVIA Y TRATAMIENTOS PREVIOS}

En 21 casos (65.6\%) no se consignó en la historia clínica éste dato; en 8 (25\%) existía el antecedente de cervicitis, en 2 casos no había antecedente de patología y en un caso se refirió pólipo endocercival. En 20 casos (62.5\%) no se informaron tratamientos previos. Todas las cervicitis habían recibido tratamiento médico.

\section{HALLAZGOS CITOLOGICOS $Y$ COLPOSCOPICOS}

La tabla No. 11A reune los hallazgos citológicos; la mayoría de las pacientes tenían citología Pap 3 (13 casos; 40.6\%) y Pap 4 (9 casos; $28.1 \%$ ). Hubo cuatro casos (12.5응 con citología Pap 5 y dos (6.2응) con citología Pap 2. En dos casos no se tomó citología nuevamente en el hospital y en otros 2 no se informó. La colposcopia sólo se hizo en 8 casos de los cuales fue sospechosa en 6 y negativa en 2 . En el $75 \%$ de los casos no se hizo colposcopia. Tabla No. 11B

TABLA No. 11A

HALLAZGOS CITOLOGICOS EN LAS PACIENTES CON NIC

\begin{tabular}{|c|c|c|}
\hline HALLAZGOS & $\#$ & $\%$ \\
\hline Pap 1 & 0 & 0.0 \\
\hline Pap 2 & 2 & 62 \\
\hline Pap 3 & 13 & 40.6 \\
\hline Pap 4 & 9 & 28.1 \\
\hline Pap 5 & 4 & 12.5 \\
\hline Sin informe & 2 & 6.2 \\
\hline Ne se tome & 2 & 6.2 \\
\hline TC TAL & 32 & 100.0 \\
\hline
\end{tabular}

TABLA No. 11B.

HALLAZGOS COLPOSCOPICOS EN LAS PACIENTES CON NIC

\begin{tabular}{|l|c|c|}
\hline HALLAZGC & $\#$ & $\%$ \\
\hline No se hizo & 24 & 75.0 \\
\hline Sospechoso & 6 & 18.7 \\
\hline Negativa & 2 & 6.2 \\
\hline TOTAL & 32 & 100.0 \\
\hline
\end{tabular}

J. CORRELACION CITOLOGICA, COLPOSCOPICA E HISTOLOGICA

Para el primer grupo de biopsias se muestra en la tabla No. 12 la correlación 
entre la citología, la colposcopia y la biopsia. En los 6 casos con colposcopia sospechosa se confirmó biopsia positiva. En dos casos la colposcopia fue negativa y la biopsia mostró displasia moderada y severa.

TABLA No. 12

CORRELACION ENTRE LA CITOLOGIA LA COLPOSCOPIA Y LA

1a. BIOPSIA EN LA NIC

\begin{tabular}{|l|c|c|}
\hline \multirow{4}{*}{ COLFC SCOPIA } & CITOLOGIA & BIOPSIA \\
\hline \multirow{5}{*}{ SOSECHCSA } & Pap 3 & CIS \\
\cline { 2 - 3 } & Pap 3 & NIC 2 \\
\cline { 2 - 3 } & Pap 4 & NIC 2 \\
\cline { 2 - 3 } & Pap 4 & CIS \\
\cline { 2 - 3 } & Pap 5 & CIS \\
\cline { 2 - 3 } & Pap 5 & CIS \\
\hline \hline \multirow{2}{*}{ NEGATIVA } & Pap 3 & NIC 2 \\
\cline { 2 - 3 } & Pap 4 & DS \\
\hline
\end{tabular}

DS = Displasia severa.

$\mathrm{CIS}=$ carcinoma in situ.

\section{K. CORRELACION CITOLUGICA E HISTOLOGICA (1a. SERIE)}

Se contó con 27 casos con registro de citología y biopsia. Hubo correlación en 13 casos (48.1응 y fal ta de correlación en 14 (51.8\%). Entre las que hubo correlación, la mayoría ( 5 casos) corresponden a citología y biopsias con diagnóstico de CIS, seguidos de correlación para displasia severa (DS) en 3 casos. En los casos en que fal tó la correlación, la mayoría (10 casos) corresponden a un resultado citológico más severo que el de la biopsia; en la mitad de los casos se trató de citologías Pap 3 y biopsias compatibles con displasia ligera. En los 4 casos restantes sin correlación, la biopsia mostró una lesión más severa que la que sugería la citología.

\section{CORRELACION ENTRE LA CITO- LOGIA Y TODAS LAS BIOPSIAS}

Se hizo un segundo estudio histopatológico en 8 casos (57.1응 de los 14 en los cuales faltaba correlación cito-patológica. En 6. se hizo por segundo set de biopsias y en 2 por conización diagnóstica. Cuando se comparan los dos sets de biopsias, en 5 casos el resultado coincidió (62.5\% de los casos con doble set); en 2 casos (25\%) la lesión fue más severa en el segundo set $y$ en otro fue menos severa. Cuando se comparó la correlación entre el segundo set de biopsias y la citología que motivó éste segundo estudio, se encontró que en cinco casos (62.5\% de las pacientes con doble set), nuevamente la biopsia mostró lesiones menores que la citología, concordando con la primera biopsia. En un caso la segunda biopsia mostró que la citología era correcta para CA infiltrante que no se había diagnosticado en la primera serie y en otro caso, la segunda biopsia (cono) concordó con la primera en que la lesión era un CIS y no un infiltrante como sugería la citología (tabla No 13).

\section{TRATAMIENTO}

La tabla No. 14 muestra las modalidades de tratamiento empleadas en todas las pacientes y la tabla No. 15 distribuye los tratamientos según el tipo de NIC para el cual se empleó. 
TABLA No. 13

\section{CORRELACION ENTRE LA CITOLOGIA Y LA SEGUNDA BIOPSIA EN LAS PACIENTES CON INCONGRUENCIAS ENTRE LA CITOLOGIA Y LA PRIMERA BIOPSIA}

\begin{tabular}{|c|c|c|c|c|c|c|}
\hline CITCLCGIA & $1 \stackrel{B}{B x}$ & 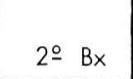 & $3 \mathrm{Bx}$ & Cono & $\begin{array}{l}2 \cong \text { Biopsia } \\
\text { vs. } 10\end{array}$ & $\begin{array}{l}2=\text { Biopsia } V_{s} \text {. } \\
\text { citología }\end{array}$ \\
\hline DS & NIC 2 & NIC 2 & No se hì & & Correlación & Menor \\
\hline CA infiltrante & NIC 3 & NIC 3 & $"$ & & Correloción & Menor \\
\hline CIS & NIC 2 & Cervicitis & $"$ & & Menor & Menor \\
\hline DS & NIC 3 & NIC 3 & " & & Correlación & Mayor \\
\hline DS & NIC 1 & & & NIC 2 & Mayor & Menor \\
\hline CA infiltrante & NIC 3 & & & NIC 3 & Correlación & Menor \\
\hline DS & NIC 3 & NIC 3 & $"$ & & Correl ación & Correlación \\
\hline CA infiltrante & NIC 3 & CA infilt. & " & & Mayor & Correlación \\
\hline
\end{tabular}

$\mathrm{DS}=$ Displasia severa. $\mathrm{CIS}=$ Carcinoma in situ.

\section{N. CORRELACION ENTRE DIAGNOSTICO PREOPERATORIO Y LA PATOLOGIA DEFINITIVA}

Se cuenta con 14 casos con estudio de patología de piezas quirúrgicas (patología definitiva). La tabla No. 16 muestra la correlación con el diagnóstico preoperatorio observándose buena correlàción (6 casos; 42.8 \%) entre la patología de la pieza de histerectomía y el diagnóstico inicial, en particular tratándose del CIS. En 3 casos se observaron lesiones menores y en sólo uno se encontró carcínoma infiltrante oculto cuando el diagnóstico inicial había sido CIS. En un sólo caso de conización hubo correlación con las biopsias iniciales; en 3 la lesión fue más severa y en 2 menos que la sospechada inicialmente.

\section{N. MORBILIDAD DEL CONO E HISTERECTOMIA}

No hubo ninguna complicación de la conización diagnóstica y/o terapéutica en éste estudio (en total siete casos). En 8 pacientes histerectomizadas no hubo complicaciones (66.6\%) y en 3 (25\%) ocurrió infección. No hubo mortalidad. (tabla No. 17). 
TABLA No. 14

TRATAMIENTOS DE LAS

PACIENTES CON NIC 1-3

\begin{tabular}{|l|c|c|}
\hline TIPO DE TRATAMIENTO & $\#$ & $\%$ \\
\hline Histerectomía Abdoninal Amp. & 12 & 37.5 \\
\hline Ninguno & 5 & 15.6 \\
\hline Conización & 4 & 12.5 \\
\hline Médico & 3 & 9.3 \\
\hline Electrocauterización & 2 & 6.2 \\
\hline Criocirugía & 0 & 0.0 \\
\hline Sin dato & 6 & 18.7 \\
\hline & 32 & 100.0 \\
\hline
\end{tabular}

\section{O. SEGUIMIENTO}

Se consigna seguimiento de 18 pacientes (56.2\%), 11 pacientes perdidas de la consulta (34.3응 y 3 trasladadas al NIC $(9.3 \%$. $)$. Se logró seguimiento de 5 años o más en 7 casos; en 6 casos el seguimiento no alcanzó a 1 año y en 5 estuvo entre 1 y 4 años. El seguimiento máximo fue de 6 años. En el momento de la últimá consulta todas las pacientes seguidas estaban libres de enfermedad pero no se puede hablar de curación sino en 7 casos. Tabla 18.

\section{P. VARIABLES SIN INFORMACION}

Ya se mencionaron algunas que investigan conceptos epidemiológicos de la enfermedad. Las historias carecen además de información acerca del número de cuadrantes positivos en la patología y del número de cortes realizados. El alto índice de deserción no permite analizar cabalmente la persistencia o recidiva de la lesión.

\section{COMENTARIO Y CONCLUSIONES}

1. A pesar de ser un número bajo de pacientes, se observa mayor incidencia de formas avanzadas del CA de cervix (3.79 por mil) comparada con la NIC (1.11 por mil) al contrario de las tendencias actuales de los países desarrollados donde aumenta la frecuencia del diagnóstico en fases más tempranas de la enfermedad (tabla No. 1).

2. El promedio de edad de las pacientes fue 39.7 años; más al to que el observado en otros estudios para la NIC. Cabe anotar que la paciente mayor (61 años) tuvo el diagnóstico de NIC-1. La mayoría de las pacientes (19 casos; 59.3\%) presentaban NIC-3 y entre éstas, 13 casos (40.6\%) tenían carcinoma in situ (CIS). Esto probablemente refleja la mayor frecuencia de estudio histológico de biopsias cuando la citología reporta hallazgos compatibles con lesiones intraepiteliales más avanzadas. La edad de las pacientes con CIS fue 10 años mayor que la de las pacientes con diṣplasia severa (DS), pero no hubo diferencia entre las edades de las pacientes con distintos tipos de NIC (tabla No.2).

3. La mayoría de las pacientes se detectaron en el examen de rutina (43.7응 destacando la importancia del frotis de Papanicolaou como parte integral del examen ginecológico. La metrorragia no es un signo precoz de NIC pero lleva la paciente a la consulta donde se toma 
TABLA No. 15

TRATAMIENTO DE LAS PACIENTES CON NIC SEGUN EL TIPO DE LESION

\begin{tabular}{|c|c|c|c|c|c|c|}
\hline $7^{N I C}$ & NIC I & NIC 2 & & NIC 3 & & TOTAL \\
\hline TRATAMIENTO & & & $\overline{D S}$ & CIS & TOTAL & \\
\hline Ninguno & 2 & 2 & 1 & & 1 & 5 \\
\hline Médico & 2 & 1 & & & & 3 \\
\hline Electrocauterización & 1 & 1 & & & & 2 \\
\hline Conización & 1 & & 2 & & 2 & 3 \\
\hline Histerectomía Abdominal Amp & & & 2 & 10 & 12 & 12 \\
\hline Sin dato de trataniento & 1 & 1 & 1 & 3 & 4 & 6 \\
\hline Sin cato de la biopsia inicial & & & & & & 1 \\
\hline TOTAL & 7 & 5 & 6 & 13 & 19 & 32 \\
\hline
\end{tabular}

rutinariamente la citología y ésto probablemente explique por qué ocupa el segundo lugar entre los motivos de consulta. En tercer lugar se encuentra el flujo vaginal (6.2\%); no hubo ningún caso de hemorragia postcoito que también es signo de lesiones avanzadas (tabla No. 8).

4. Se encontró sólo una paciente embarazada (3.1\%). La paciente tenía un CIS y se trató con histerectomía abdominal-ampliada después del parto. Se insiste en la necesidad de la citología vaginal como parte del examen prenatal.

5. Con excepción de dos pacientes, tođas fueron multigestantes (más de 5 gestaciones) y multíparas (más de 3 partos) pero no hay diferencias significativas en el número de gestaciones y la paridad entre los distintos tipos de NIC en éste estudio (tabla No. 9). Una paciente con CIS era nuligestante $y$ otra primípara.

6. La edad del primer parto aparece consignada en el $72 \%$ de los casos; no hubo diferencias entre los distintos tipos de NIC con respecto a éste factor de riesgo en éste estudio. La edad del primer coito solamente se consignó en 14 casos (43이); las dos pacientes con inicio más temprano de las relaciones sexuales tenían displasia severa y carcinoma in situ reafirmando la importancia de éste factor 
TABLA No. 16

CORRELACION ENTRE EL DIAGNOSTICO PREOPERATORIO Y LA PATOLOGIA DEFINITIVA EN PIEZAS QUIRURGICAS

\begin{tabular}{|c|c|c|c|c|}
\hline $\begin{array}{c}\text { Diagnóst } \\
\text { previo }\end{array}$ & $\begin{array}{l}\text { AP del } \\
\text { cono }\end{array}$ & $\begin{array}{l}\text { AP del } \\
\text { útero }\end{array}$ & $\begin{array}{l}\text { AP del ce } \\
\text { ho } V_{s} D x\end{array}$ & $\begin{array}{l}\text { AP útero } \\
\text { ss Dx prev }\end{array}$ \\
\hline $\mathrm{CIS}$ & & CIS & & Correlacio \\
\hline $\mathrm{CIS}$ & & CIS & & 11 \\
\hline $\mathrm{CIS}$ & & $\mathrm{ClS}$ & & " \\
\hline टा5 & & $\mathrm{CIS}$ & & $"$ \\
\hline CIS & & CIS & & $"$ \\
\hline CIS & $\mathrm{CIS}$ & & Correlaci & \\
\hline DS & CIS & DS & Mayer & 11 \\
\hline$\overline{D S}$ & Cervicitis & & Menor & \\
\hline $\mathrm{DL}$ & $D M$ & & Mayor & \\
\hline $\mathrm{ClS}$ & & Cervicitis & & Menor \\
\hline DS & DM & & Menor & \\
\hline $\mathrm{CIS}$ & & Cervicits & & Menor \\
\hline DS & CIS & DM & Mayor & Menor \\
\hline CIS & & Infiltrante & & Mayor \\
\hline & & . & & \\
\hline
\end{tabular}

TABLA No. 17

MORBILIDAD POSTCONIZACION E HISTERECTOMIA EN EL MANEIO DE LA NIC

\begin{tabular}{|l|c|c|c|c|}
\hline \multirow{2}{*}{ INTERVENC. } & \multicolumn{2}{|c|}{ H.A.A. } & \multicolumn{2}{|c|}{ CONIZACICN } \\
\cline { 2 - 5 } & $\#$ & $\%$ & $\#$ & $\%$ \\
\hline SIN CUMPILIDAD & & & & \\
\hline INFECCION & 3 & 25.0 & & \\
\hline HEMATCMA DE & & & & \\
LA CUPULA & 1 & 8.3 & & \\
\hline
\end{tabular}

de riesgo y enfatizando la necesidad de consignar en la historia clínica todos los datos relacionados con la epidemiología de la NIC (tabla No. 10).

TABLA No. 18

\section{SEGUIMIENTO DE LAS PACIENTES CON NIC}

\begin{tabular}{|c|c|c|}
\hline ESTADO EN ULTIMO CONTRQ & $\#$ & $\%$ \\
\hline Sin evidencia de enfermedad & 18 & 56.2 \\
\hline Perdidas de la consul ta & 11 & 34.3 \\
\hline Remifidas al INC & 3 & 9.3 \\
\hline TOTAL & 32 & 100.0 \\
\hline
\end{tabular}

PACIENTES SIN EVIDENCIA DE ENFERMEDAD DISTRIBUIDAS SEGUN LA DURACION DEL SEGUIMIENTO

\begin{tabular}{|c|c|c|}
\hline DURACION DEL SEGUIMIENT & $\#$ & $\%$ \\
\hline Menor de un año & 6 & 33.3 \\
\hline a 4 años & 5 & 15.6 \\
\hline 5 y mas años & 7 & 21.8 \\
\hline TOTAL & 18 & 100.0 \\
\hline
\end{tabular}

7. Como la edad del primer coito, no se investiga $y / o$ consigna el número de compañeros sexuales de las pacientes con NIC siendo factores de riesgo de conocida importancia.

8. El método de anticoncepción más usado fue el DIU (34.3응 seguido de la combinación de métodos (12.5\%); se encontró una proporción igual de pacientes que no planificaban (12.5\%), (tabla No. 11). Los métodos de anticoncepción no se han relacionado directamente con la génesis de la NIC pero favorecen el inicio y sostenimiento de las relaciones sexuales en forma más precoz.

9. No se puede analizar la patología previa y su tratamiento por el subregistro importante de éstos datos en la historia clínica. 
10. La mayoría de las pacientes tenían citología Pap 3 (13 casos; 40.6\%) lo cual refleja el hecho de iniciar el estudio en pacientes con hallazgos sospechosos de malignidad. En 9 casos (28.1\%) la citología fue Pap 4 y en 4 casos (12.5\%) fue Pap 5. En 2 casos (6.2\%) la citología fue Pap 2 pero se debe seguir ampliando la colposcopia y toma de biopsias dirigidas a pacientes con citología Pap 2 con frotis inflamatorio persistente. Así mismo debe tomarse siempre citología dirigida cuando la paciente ingresa a la clínica de tumores.

\section{En los 6 casos de colposcopia sospe-} chosa (100\%) se confirmó patología en la biopsia. Hubo dos falsos negativos en la colposcopia en los cuales se demostró displasia moderada en uno y severa en otro. En 4 casos (66.6\%) de colposcopias sospechosas, la biopsia demostró CIS (verdaderos positivos) y en los otros 2 displasia moderada. La anormalidad vascular en las lesiones intraepiteliales más avanzadas (CIS) es mayor, lo cual probablemente explique la mejor correlación en éstos casos entre colposcopia y biopsia. No se hizo en todas las pacientes investigadas por citología Pap 3 o mayor la colposcopia; sólo un 25\% de pacientes con citología anormal tenían estudio colposcópico, por lo tanto, la biopsia no se hizo siempre bajo visión colposcópica lo cual puede llevar a errores diagnósticos. Se insiste en la investigación colposcópica y tiopsia dirigida como parte indispensable del estudio de pacientes con hallazgos citológicos anormales.

12. Aproximadamente en la mitad de los casos faltó correlación entre la citología y la biopsia; especialmente (10 casos), por resultado citológico más severo que el de la biopsia. En sólo 4 casos la patología mostró una lesión más severa que la sugerida por la citología. La mejor correlación existió entre la citología y la biopsia para CIS y DS. Estos hallazgos reflejan la baja frecuencia con que se hizo el estudio colposcópico y confirman la necesidad de practicar citología y biopsia dirigidas colposcópicamente para mejorar la correlación clínico-patológica y la fineza del diagnóstico y del tratamiento en pacientes con patología cervical.

13. No se siguieron las indicaciones para el segundo grupo de biopsias y para conización diagnóstica en todos los casos en los que faltaba correlación entre la citología y la biopsia; sólo en 8 casos, (57.1\% de las 14 pacientes) se hizo el segundo estudio histológico. Hubo al ta correlación entre los dos grupos de biopsias (62.5\%); en 2 casos la lesión fue más severa en la segunda biopsia que en la primera y en uno de éstos demostró un CA infiltrante que sugería la citología. Las dos biopsias se correlacionaron entre sí con mayor frecuencia al demostrar lesiones menos severas que las que sugería la citología (62.5\%). Se insiste en la necesidad de practicar el segundo grupo de biopsias siempre que se estudia una paciente con citología anormal y aplicar en el hospital todas las indicacionesdel cono diagnóstico con el fin de mejorar el manejo de éstas pacientes (tabla No. 13).

14. El tratamiento más frecuente fue la histerectomía abdominal ampliada realizada en 12 casos (37.5\%), seguida por la conización en 4 casos (12.5\%), reflejando la mayor frecuencia del NIC-3 detectada en éste estudio. En la DS se hicieron igual número de conizaciones y de histerectomía (2 de cada una) pero el CIS se trató únicamente con histerectomía $\mathrm{Ab}$ dominal Ampliada, lo cual refleja posiblemente el deseo de un tratamiento 
definitivo ante una población de difícil seguimiento. Sólo se cuenta en el hospital con la electrocauterización como método de tratamiento local y ambulatorio y se realizó en un caso de displasia leve y en otro de displasia moderada. La tendencia mundial actual es hacia el tratamiento ambulatorio - local y se requiere en el hospital de la consecución del criocauterio para tal fin y para realizar estudios comparativos con otros métodos de tratamiento. En 4 casos de NIC tempranas no se realizó ningún tratamiento y la tendencia actual es a tratar todas las NIC si se consideran un continuum hasta la lesión maligna; pero estos casos serían valiosos si hubiera seguimiento adecuado para detectar si la lesión ha progresado o no. Debe incentivarse el uso de la conización terapéutica en el hospital (tabla No. 15).

15. En 14 casos se cuenta con diagnóstico patológico definitivo en piezas quirúrgicas de histerectomía y conización. En el CIS hubo buena correlación entre el diagnóstico preoperatorio y el definitivo en piezas de histerectomía (42.8응 y en 3 casos la lesión fue menos severa. La correlación entre el diagnóstico inicial y la pieza del"cono ocurrió solamente en un sólo caso; en 3 casos la lesión fue más severa que lo sugerido por las biopsiàs iniciales. En 2 casos de CIS sólo se encontró cervicitis en la pieza de histerectomía posiblemente por extirpación total de la - lesión previamente. En la histerectomía se hizo el diagnóstico de un CA infiltrante oculto cuyo diagnóstico previo era CIS. La biopsia dirigida empleada de rutina mejorará la correlación entre éstos hallazgos (tabla No. 16).
16. La morbilidad postoperatoria fue baja, no hubo ningún caso en la conización $y$ el $66.6 \%$ de las pacientes histerectomizadas evolucionaron bien. La complicación más frecuente posthisterectomía fue la infección: 3 casos (25\%), tabla No. 17.

17. Sólo se siguieron 18 pacientes (56.2응 con una deserción del 34.3\% (11 pacientes) y el seguimiento fue de 5 años o más en sólo el $21.8 \%$ de los casos; en los demás fue menor y fue menor de un año en un tercio de los casos. Esto refleja una deficiente labor de educación a la paciente respecto a su patología y el desinterés de quienes deben localizar las pacientes para insistir en su control. Para el momento en que se realizó el trabajo, el último control se había hecho, en general, por lo menos un año antes.

Sin los datos de seguimiento, a pesar de estar libres de enfermedad las pacientes aquí mencionadas, sólo se puede hablar de curación en 7 casos (seguimiento de 5 años o más), de los cuales 4 tenían CIS y fueron tratadas con histerectomía abdominal ampliada (tabla No. 18).

18. No se puede analizar un grupo de variables que influyen el pronóstico de las pacientes por ausencia de datos en las historias clínicas y por defecto en el seguimiento de las pacientes. Se diseña un formulario de historia clínica precodificado (formulario No. 1) y se anexa a la historia de la clínica de tumores. Se insiste en la necesidad de unificar criterios diagnósticos y terapéuticos que permitan iniciar estudios prospectivos sobre la NIC en el hospital y se requiere fortalecer el servicio de trabajo social para la labor de seguimiento de las pacientes. 


\section{BIBLIOGRAFIA}

1. FU, Y.S., REAGAN, J.W., and RICHART, R.M.: Definition of precursors. Gynecol Oncol, 1981. 12: S220-S231.

2. REAGAN, J.W., and PATTEN, S.F.: Dysplasia: a basic reaction to injury in the uterine cervix. Ann N.Y. Acad Sci, 1962. 97: 662-682.

3. RICHART, R.M.: Cervical Intraepiteliai neoplasia, en Pathology Annual 1973. S.C. Sommers, Ed. Appleton-CenturyCrofts. New York, pp. 301-328.

4. HANDLEY, W.S.: The prevention of cancer. Lancet, 1936. 1987-991.

5. KESSLER, I.I.: Etiological concepts in cervical carcinogenesis. Gynecol Oncol, 1981. 12: S7-S24.

6. KOSS, L.G,: Epidemoid carcinoma of the uterine cervix and related precancerous lesions. Diagnostic cytology and its histopathologic bases. Koss LGed. Philadelphia, J.B. Lippincott, Vol 1, 533, 1980.

7. SALVATORE, C.A.: High-risk factors in gynecologic and breast cancer (meeting abstract). Third world conference of human reproduction, March 22-26, 1981. Berlin, West Germany. International Academy of Reproductive medicine 500 pp, 1981.

8. BARBER, H.R.: Uterine cancer (prevention). Cancer, 1981. 17 (5, Suppl): 1126-1132.

9. FENÓGLIO, G.M., and FERENZY, A.: Etiologic factors in cervical neoplasia. Semmin Oncol, 1982. 9: 349-372.
10. DE BRUX, J.: The natural history of precancerous lesions and carcinoma in situ. Gynecologie, 1982. 33: 215-220.

11. MARTIN, C.E.: Marital and coital factors in cervical cancer. Am J. Public health, 1967, 57: 803-814.

12. WYNDER, E.L., CORNFIELD, I., SCHORFF, P.D., et al.: A study of environmental factors in carcinoma of the cervix. Am. J. Obstet. Gynecol. 1954. 68: 1016-1052.

13. BUCKLEY, J.D., DOLL, R., HARRIS, R.W., et al.: Case-control study of the husbands of women with dysplasia of carcinoma of the cervix uteri. Lancet, 1981. 2: 1010-1015.

14. COPPLESON, M., and REID, B.: The etiology of squamous carcinoma of the cervix. Obstet. Gynecol, 1968. 32: 432. 436 .

15. SIMECKOVA, M., LONSER, E., NICHOLS, E.E., et al.: Chronic tricomoniasis and cervical cancer. Obstet. Gynecol, 1962. 20: 410-412.

16. NAIB, Z.M., NAHAMIAS, A.J., JOSEY W.E., et al.: Genital hërpetic infection association with cervical dysplasia and carcinoma. Cancer, 1969. 23: 940-945.

17. RAWLS, W.E., TOMPKINS, W.A.F., FIGUEROA, ME., et al.: Herpes virus type-2: Association with carcinoma of the cervix. Science, 1968 161: 1255 . 1256.

18. AURELIAN, L., STRANDBERG, J.D., MELENDEZ, L.V., et al.: Herpes virus type 2 isolated from cervical tumor cells grown in tissue culture, Science, 1971. 174: 704-707. 
19. MIZELL, M., TOPLIN, I., and ISAACS, J.S.: Tumor induction developing from kidneys bay a zonal centrifugate fraction of the frog herpes-type virus. Science. 1969. 165: 1134-1137.

20. KESSLER, I.I.: Human cervical cancer as a venereal disease. Cancer Res, 1976. 36: 783-791.

21. KESSLER, I.I.: On the etiology and prevention of cervical cancer - a status report. Obstet. Gynecol Surv, 1980. 34: $790-794$.

22. FISH, E.N., TOBIN, S.M., COOTER, N.B., et al.: Update on the relation of herpesvirus hominis type II to carcinoma of the cervix. Obstet. Gynecol, 1982. 59: 220-224.

23. GRUNEBAUM, A.N., SEDILIS, A. SILLMAN, F., et al.: Association of human papillomavirus infection with cervical intraepithelial neoplasia. Obstet Gynecol, 1983, 62: 448-455.

24. FRANCESCHI, S., DOLL, R., GALLWEY, J., et al.: Genital warts and cervical neoplasia: an epidemiological study. Br. J. Cancer, 1983. 48: 621-8.

25. REID., R.: Genital warts and cervical cancer, II: Is human papilomavirus infection the trigger to cervical carcinogenesis? Gynecol Oncol, 1983. 15 (2): 239-52.

26. KURMAN, R.J., JENSON, A.B., and LANCASTER, W.D.: Papilomavirus infection of the cervix. II: Relationship to intraepithelial neoplasia based on the presence of specific viral structural proteins. Am. J. Surg. Pathol, 1983, 7: 39-52.
27. BAIRD, P.J.: Serological evidence for the association of papillomavirus and cervical neoplasia, Lancet, 1983. 2: 17-8.

28. LAMBERT, B., BRISSON, G., and BIELMAN, P.: Plasma vitamin $A$ and precancerous lesions of the cervix uteri: a preliminary report. Gynecol Oncol, 1981. 11: 136-139.

29. BUTTERWOTH, C.E., HATCH, K.D., MUELLER, $H$., et al.: Folate-induced regression of cervical intraepithelial neoplasia (CIN) in users of oral contraceptive agents (OCA) (meeting abstract). Am. J. Clin. Nutr. 1980. 33: 926.

30. ROMMEY, B., PALAN, P.R., DUTTAGUPTA, C., et al.: Retinoids and the prevention of cervical dysplasias. Am. J. Ostet Gynecol, 1981. 141: 890894.

31. VALENTE, S.: Diagnosis and treatment of preinvasive and microinvasive cervicocarcinoma. Eur. J. Gynaecol Oncol. 1982. 3: 91-5.

32. BERHMAN, S.J.: The annual Pap smear: Justifiable? Hosp Pract, 1981. 16: 10, 17.

33. POPKIN, D.R.: Treatment of cervical intraepithelial neoplasia with the carbon dioxide laser. Am. J. Obstet. Gynecol, 1983. 145: 177-180.

34. RICHART, R.M., CRUM, C.P., and TOWNS, D.E.: Workup of the patient with an abnormal Papanicolaou smear. Gynecol Oncol, 1981. 12: S265-S276.

35. TOWNSEND, D.E., RICHART, R.M., MARKS, E., et al.: Invasive cancer following outpatient evaluation and the- 
rapy for cervical disease. Obstet Gynecol, 1981. 57: 145-149.

36. JONES III, H.W.: Cone biopsy in the management of cervical intraepithelial neoplasia. Clin. Obstet. Gynecol, 1983. 26: $968-79$.

37. LUCAS, W.E.: Cervical cancer: What's the latest in diagnosis and therapy? Contemp Ob/Gyn, 1979. 14: 19-24.

38. LANSAC, J.: Precancerous states of the uterine cervix. Diagnosis and treatment. Bull Canaer (Paris), 1979. 66: 435-46.

39. CREASMAN, W.T., CLARKE-PEARSON, D.L., and WEED, J.C.: Results of outpatient therapy of cervical intraepithelial neoplasia. Gynecol Oncol, 1981. 12: S306-S316.

40. SINGER, A., and WALKER, P.: What is the optimum treatment of cervical premalignancy? Brit J. Obstet. Gynaec 1982. 89: 335-337.

41. MONAGHAN, J.M., KIRKUP, W., DAVIS, J.A., et al.: Treatment of cervical intraepithelial neoplasia by colposcopically directed cryosurgery and subsequent pregnancy experience. Brit. J., Obstet Gynaec, 1982. 89: 387-392.

42. BAGGISH, M.S., Laser management of cervical intraepithelial neoplasia. Clin. Obstet. Gynecol, 1983. 24: 980-995.

43. CONEY, P., WALTON, L.A., EDELMAN, D.A., et al.: Cryosurgical treatment of early cervical intraepithelial neoplasia. Obstet. Gynecol, 1983. 62: 463-466.
44. KAUFMAN, R.H., STRAMA, T., NORTON, P.K., et al.: Cryosurgical treatment of cervical intraepithelial neoplasia. Obstet. Gynecol, 1973. 42: 881.

45. SAIDI, M.H., WHITE, A.J., WEINBERG, P.C.: The hazzard of cryosurgery for treatment of cervical dysplasia. J. Reprod. Med, 1977. 19: 70.

46. TREDWAY, D.R., TOWNSEND, D.E HOVLAND, D.N., et al.: Colposcopy and cryosurgery in cervical intraepithelial neoplasia. Am. J. Obstet. Gynecol, 1972. 14: 1020 .

47. POPKIN, D.R., SCALI, V., and AHMED, M.N.: Cryosurgery for treatment of cervical intraepithelial neoplasia. Am. J. Obstet. Gynecol, 1978. 130-551.

48. TOWNSEND, D.E.: Cryosurgery for CIN. Obstet Gynecol Surv, 1979. 34:, 838 .

49. KAUFMAN, R.H., and IRWIN, J.F.: The cryosurgery therapy of cervical intraepithelial neoplasia III. Continuing followup. Am. J. Obstet Gynecol, 1978, $131: 381$.

50. CREASMAN, W.T., WEED, J.C., CURRY, S.L., et al.: Efficacy of cryosurgical treatment of severe cervical intraepithelial neoplasia. Obstet. Gynecol, 1973, 41: 501.

51. RICHART, R.M., TOWNSEND, D.E., CRISP, W., et al.: An analisis of "long term" followup results in patients with cervical intraepithelial neoplasia treated with cryosurgery. Am. J. Obstet. Gynecol, 1980. 137: 823 .

52. RICHART, R.M., and SCIARRA, J.I.: Treatment of cervical dysplasia by out- 
patient electrocauterization. Am. J. Obstet Gynecol, 1968. 101: 200.

53. ORTIZ, R., NEWTON, M., and TSAI, A.: Electrocautery treatment of cervical intraepithelial neoplasia. Obstet Gynecol, 1973. 41: 113.

54. HOLLYOCK, V.E., and CHANEN, W.: Electrocoagulation diathermy for treatment of cervical dy splasia and carcinoma in situ. Obstet Gynecol, 1976. 47: 196.

55. CHANEN, W.: Electrocoagulation diathermy of cervical intraepithelial neoplasia. Obstet. Gynecol Surv, 1979 34:829.

56. CHANEN, W.: Treatment of CIN by destruction-electrocoagulation diathermy in preclinical neoplasia of the cervix (Jordan, J.A., Sharp, F. \& Singer, A., Eds), Proc Study Group, RCOG, London.

57. BYRON, J.M., KRANTZ, K., et al.: The carbon dioxide laser in cervical in traepithelial neoplasia: a five-year experience in treating 230 patients. Am. J. Obstet Gynecol, 1981. 139:565.

58. BURKE, H., LOVELL, L., and ANTONIOLO, D.: Carbon dioxide laser therapy of cervical intraepithelial neopla- sia: factors determining success rate. Lasers Surg Med, 1980. 1: 113.

59. BAGGISH, M.S.; High-power density carbon dioxide laser therapy for early cervical neoplasia. Am. J.Obstet. Gynecol, 1980. 136:117.

60. DUNCAN, I.D.: The Semm "cold" coagulator in the management of cervical intraepithelial neoplasia. Clin. Obstet. Ginecol, 1983. 26: 996-1006.

61. ANDERSH, B., and MOINIAN, M.: Diagnostic and therapeutic viewpoints on cervical intraepithelial neoplasia. 10 year follow-up of a conization material, Gynecol Obstet Invest, 1982. 13: 193 205.

62. DUNCAN, I.D.: Treatment of CIN by destruction with the Semm "cold" coagulator. In preclinical neoplasia of the cervix (Jordan, J.A., Sharp, F.\& Singer, A., Eds) Proc. Study Group RCOG, London).

63. KOLSTAD, P., and KLEM, V.: Long term followup of 1121 cases of $\mathrm{Ca}$ in situ. Obstet Gynecol, 1976. 42: 125.

64. JONES III, H.W., and BULLER, R.: The treatment of cervical intraepithelial neoplasia by cone biopsy. Am. J. Obstet Gynecol, 1980. 137: 882. 